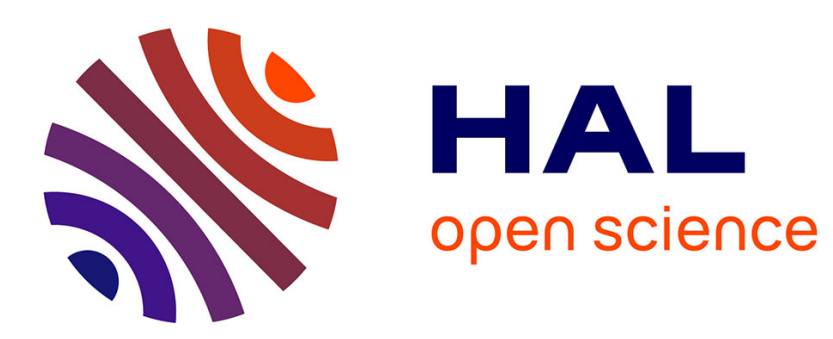

\title{
Biocompatible gold nanoclusters: synthetic strategies and biomedical prospects
}

Guy Zuber, Etienne Weiss, Manuela Chiper

\section{To cite this version:}

Guy Zuber, Etienne Weiss, Manuela Chiper. Biocompatible gold nanoclusters: synthetic strategies and biomedical prospects. Nanotechnology, 2019, 30 (35), pp.352001. 10.1088/1361-6528/ab2088 . hal-02867604

\section{HAL Id: hal-02867604 https://hal.science/hal-02867604}

Submitted on 27 Aug 2020

HAL is a multi-disciplinary open access archive for the deposit and dissemination of scientific research documents, whether they are published or not. The documents may come from teaching and research institutions in France or abroad, or from public or private research centers.
L'archive ouverte pluridisciplinaire $\mathbf{H A L}$, est destinée au dépôt et à la diffusion de documents scientifiques de niveau recherche, publiés ou non, émanant des établissements d'enseignement et de recherche français ou étrangers, des laboratoires publics ou privés. 
ACCEPTED MANUSCRIPT

\section{Biocompatible gold nanoclusters: synthetic strategies and biomedical prospects}

To cite this article before publication: Guy Zuber et al 2019 Nanotechnology in press https://doi.org/10.1088/1361-6528/ab2088

\section{Manuscript version: Accepted Manuscript}

Accepted Manuscript is "the version of the article accepted for publication including all changes made as a result of the peer review process, and which may also include the addition to the article by IOP Publishing of a header, an article ID, a cover sheet and/or an 'Accepted Manuscript' watermark, but excluding any other editing, typesetting or other changes made by IOP Publishing and/or its licensors"

This Accepted Manuscript is @ 2019 IOP Publishing Ltd.

During the embargo period (the 12 month period from the publication of the Version of Record of this article), the Accepted Manuscript is fully protected by copyright and cannot be reused or reposted elsewhere.

As the Version of Record of this article is going to be / has been published on a subscription basis, this Accepted Manuscript is available for reuse under a CC BY-NC-ND 3.0 licence after the 12 month embargo period.

After the embargo period, everyone is permitted to use copy and redistribute this article for non-commercial purposes only, provided that they adhere to all the terms of the licence https://creativecommons.org/licences/by-nc-nd/3.0

Although reasonable endeavours have been taken to obtain all necessary permissions from third parties to include their copyrighted content within this article, their full citation and copyright line may not be present in this Accepted Manuscript version. Before using any content from this article, please refer to the Version of Record on IOPscience once published for full citation and copyright details, as permissions will likely be required. All third party content is fully copyright protected, unless specifically stated otherwise in the figure caption in the Version of Record.

View the article online for updates and enhancements. 


\title{
Biocompatible gold nanoclusters: synthetic strategies and biomedical prospects
}

Guy Zuber ${ }^{1}$, Etienne Weiss ${ }^{1}$, Manuela Chiper ${ }^{1,2 *}$

${ }^{1}$ Molecular and Pharmaceutical Engineering of Biologics, CNRS - Université de Strasbourg UMR 7242, Boulevard Sebastien Brant, 67412 Illkirch, France

${ }^{2}$ Faculté de Pharmacie - Université de Strasbourg, 74 Route du Rhin, F-67400 Illkirch, France

*Corresponding author: chiper@unistra.fr

https://orcid.org/0000-0002-1563-5397

Orcid Guy Zuber: 0000-0001-8032-2410

Orcid Etienne Weiss: 0000-0001-6622-6377

\begin{abstract}
The latest advances concerning ultra-small gold nanoparticles $(\leq 2 \mathrm{~nm})$ commonly known as gold nanoclusters (AuNCs) are reviewed and discussed in the context of biological and biomedical applications (labeling, delivery, imaging and therapy). A great diversity of synthetic methods has been developed and optimized aiming to improve the chemical structures and physico-chemical properties of the resulting AuNCs. The main synthetic approaches were surveyed with emphasis on methods leading to water-soluble AuNCs since aqueous solutions are the preferred media for biological applications. The most representative and recent experimental results are discussed in relationship to their potential for biomedical applications.
\end{abstract}

\section{Keywords}

gold nanoclusters, bioimaging, molecular nanoprobes, cancer imaging, cancer therapy, drug delivery 


\section{Introduction}

In the last decade, significant progress has been made in developing novel nanosystems based on gold nanoclusters (AuNCs) as reflected by a significant number of publications that has certainly not stopped growing (Figure 1). Additionally, numerous scientific studies performed with various types of gold nanosystems demonstrated that gold itself is a rather inert and biocompatible metal [1] leading to different applications [2][3][4].

The AuNCs is considered as a sub-class of gold nanoparticles (AuNPs) that distinct itself principally by an ultra-small size $(\leq 2 \mathrm{~nm})$ [5]. The structure of AuNCs consists of a metallic core containing few gold atoms and $\mathrm{Au}(\mathrm{I})$ coordinating ligands that surround and protect the core. In consequence their electronic, magnetic and optical properties differ from $>2 \mathrm{~nm}$ AuNPs [6][7]. In contrast to AuNPs, AuNCs can be even composed of countable number of gold atoms (from a few to hundred) and surrounding ligands [5][8][9]. The AuNCs containing only a few gold atoms can be considered as molecules with the majority of the constituent atoms at the interface and thus in direct contact with media (e.g. solvents) providing nanosystems characterized by extremely large surface areas reported to ultra-small volumes. Thus, the AuNCs exhibit specific physicochemical properties, placing them between isolated atoms, small molecules (such as metal-ligand complexes) and plasmonic nanoparticles [6]. Additionally, the physicochemical/properties can also be modified by varying the nature of the ligands and number of gold atoms [10].

Both (AuNCs and AuNPs) display UY/Vis absorption spectra profiles strongly influenced by their size, shape and solvent media [11]. The AuNPs ( $>2 \mathrm{~nm}$ ) commonly display a surface plasmon resonance (SPR) band, which varies with their size. However, the SPR band generally disappears for AuNCs of sizes below $2 \mathrm{~nm}$ (AuNCs of sizes inferior to 140 gold atoms) [10]. Some AuNCs can also display photoluminescence abilities. This photoluminescence or fluorescence has spurred considerable interest in the research community since the fluorescent quantum dots (QDs) are composed of toxic metal ions (e.g. cadmium, lead) whereas gold is considered biocompatible [12]. Nowadays, it is possible to select conditions and procedures to obtain fluorescent AuNCs of different absorption and emission wavelengths as well as to tailor their brightness [13].

Besides this diversity of physicochemical properties, AuNCs have an important potential for biomedical applications since generally the size is an important parameter of the ADME/PK (absorption, distribution, metabolism, excretion) profile of gold nanosystems (e.g. elimination from the body) [14][15]. Other parameters such as surface coverage [16] or route of administration could also influence the ADKME/PK profile [17] but definitely the ultra 
small size of AuNCs offer the chance of elimination by glomerular filtration, limiting longterm residence and accumulation in other organs.

The field of AuNCs is currently undergoing an impressive growth and new directions and concepts are blooming. The interest of using AuNCs consists also in making use of a large variety of techniques able to exploit the specific interactions of AuNCs with light or radiation in a special context. First of all, these interactions can be visualized by optical microscopy depending of the size of the analyzed nanoprobes. Secondly, some of AuNCs are known to be able to emit fluorescence upon photo-excitation offering the possibility to be visualized by fluorescence microscopy. Last but not least, AuNCs can convert the absorbed light into heat and this phenomenon is visualized by using photothermal imaging. Apart from the characteristic interactions with light that opened the way to different applications, AuNCs can also be visualized due to their interactions with X-ray as well as with electron waves by strongly absorbing them. These nanoprobes make use of the fact that gold is a high atomic number material $(Z=79)$ that gives high density and contrast in electron microscopy $(\mathrm{EM})$. Moreover, AuNCs scatter X-ray and this provides good contrast in computed tomographic (CT) scanning since gold has an X-ray attenuation coefficient 150-fold higher than even bone [18]. Finally, AuNCs can be radioactively labeled and thus detected by gamma radiation.

In this context, the AuNCs appear as promising nanosystems for biomedical applications. Synthetic procedures able to produce highly monodispersed AuNCs of selected size are getting robust and the current challenge is directed toward surface functionalization with bioactive molecules or drugs in an appropriate manner for biomedical applications [19]. Several reviews have been already focused on the synthesis and characterization of various types of AuNCs [20][21][22].

Herein, we offer insights on the most recent and promising research developments concerning the AuNCs prepared for biolabeling and further biomedical applications. Considering that the synthetic strategies play an essential role in establishing the specific properties of the resulting AuNCs, we structured the reviews as follows. The first section surveys the major synthetic methods for non-fluorescent AuNCs followed by examples of applications in biomedical area. The second section is focused on the preparation of fluorescent AuNCs and their potential for exploring organisms on real time and space both in vitro and in vivo. The last section provides a short outlook on the prospective of AuNCs for further improvement and biomedical applications. 


\section{Non-fluorescent gold nanoclusters}

AuNCs of precise composition were reported in the early 70's. These AuNCs do not display photoluminescent abilities but offer enough opacity to EM and X-rays making them efficient contrasting agents. Additionally, the electronic properties of these AuNCs could also find usage in enhanced radiotherapy treatment.

\subsection{Phosphine-protected gold nanoclusters}

\subsubsection{Preparation}

One of the first synthetic methods reported the preparation of $\mathrm{AuNCs}$ as $\mathrm{Au}_{11}\left(\mathrm{PPh}_{3}\right)_{7}$ having the gold core coordinated by phosphine ligands via $\mathrm{Au}(\mathrm{I})-\mathrm{P}$ bonds [23]. For a good aqueous solubility and reactivity towards proteins, the phosphine ligands were subsequently functionalized with carboxylate and maleimide groups [24-26][27]. The synthetic procedure consisted in two main steps: the phosphines were treated with $\mathrm{AuCN}$ in a methanol/ethanol solution and the resulting complex was reduced with sodium borohydride $\left(\mathrm{NaBH}_{4}\right)$ yielding a gold phosphine-protected nanocluster containing amino-groups onto the outer shell. These nucleophilic amino groups are important because they facilitate further conjugation of the AuNCs to various biomolecules. The amino group could be functionalized with a maleimide to promote the formation of a covalent bond between the AuNCs-ligand and a thiolcontaining protein in aqueous conditions. In the early ' 90 s, Hainfeld et al. developed and then commercialized $\mathrm{Au}_{67}$-phosphine maleimide conjugate named Nanogold-maleimide [28]. Another type of AuNCs capable of reacting towards the amino-groups of proteins in water (Nanogold-NHS ester) was also made available [28][29].

\subsubsection{Biological evaluations}

\section{Electron microscopy imaging}

The Nanogold ( $\mathrm{Au}_{67} \mathrm{NCs}, 1.4 \mathrm{~nm}$ ) is detectable by TEM only if is deposited alone onto an ultrathin carbon film. When buried into a slice of cellular specimen, the Nanogold is unfortunately not discernable. Nevertheless, it can be revealed using a silver enhancement strategy. Takizawa et al. carried out immunochemistry experiments on ultra-thin cryosections and compared the quality of the EM immunolabeling of lactoferrin into human neutrophils using either $1.4 \mathrm{~nm}$ Nanogold-antibody conjugates or 5-10 nm AuNPs-antibody conjugates [30]. It was observed that the $1.4 \mathrm{~nm}$ nanoprobes penetrate much deeper into cryosectioned neutrophils than the 5-10 nm nanoprobes, enhancing de facto the epitope detection accuracy. Moreover, the quality of the images was in large favor to $\mathrm{Au}_{67} \mathrm{NCs}$, justifying the 
use of a procedure that incorporates an extra silver enhancement step. The enhancement takes place due to silver deposition onto gold surface, which increases the size of the gold core, and hence its opacity to electrons [31].

In recent years, it has been made possible to analyse the same specimen by fluorescent microscopy and EM, correlating the position and field of observation. This new technic named correlative microscopy [32] relies on antibody conjugates probes that can be detected by fluorescence and EM [33]. In this context, the team of Hainfeld prepared a dual system affording both fluorescence and opacity to EM. The group discovered that the AuNCs quenches the fluorescence of fluorescein when the fluorophore was directly attached to the AuNCs-bound ligands phosphine [28]. However, the quenching of fluorescence decreased by increasing the distance between the gold and fluorophore. A fluorescent Nanogold-Fab' was therefore obtained by conjugating the fluorophore (e.g. fluoresceine) to the Fab'. This bimodal nanoprobe designed for correlative fluorescence to EM microscopy was named Fluoronanogold (FNG) [34,35].

Takizawa et al. used the FNG in immunochemistry studies and performed correlative microscopy experiments in cells and tissues [36][37]. The FNG was used as a secondary antibody to investigate the lactoferrin distribution in human neutrophils [36]. A correlation between the fluorescent and electron-opaque images was done before and after silver enhancement of the Nanogold. The results showed a clear improvement of the image resolution and offered better insights of the analysed samples. Other applications of FNG were found for labeling the microtubules in phagocytic leukocytes [38] or myeloperoxidase in ultrathin cryo-section of human neutrophils [37]. Overall FNG proved to be a powerful labeling nanoprobe for correlative microscopy.

\subsubsection{Biomedical prospects}

\section{Radiotherapy}

Hainfeld et al. investigated the properties of the phosphine-coated AuNCs and their ability to sensitize tumor cells to radiation in vivo [39]. The phosphine-coated AuNCs of $1.9 \mathrm{~nm}$ were intravenously administrated into tumor-bearing mice. The results demonstrated that these phosphine-coated AuNCs mostly accumulated into tumors and not in the liver probably due to their chemical structure. Moreover, the treated mice showed to benefit from the radiation treatment, indicating that the phosphine-coated AuNCs can sensitize the tumor cells to radiation. It has been suggested that the phosphine-coated AuNCs can enhance the therapeutic efficiency by providing a local augmented Au concentration in tumor and thus 
absorbing X-ray more efficiently than the organic surrounding molecules. In this context, the phosphine-coated AuNCs radiotherapy enhancement takes advantages of the direct interactions $\mathrm{Au} /$ radiation waves during treatment while the nanoclusters is hit with high energy. Subsequently the phosphine-coated AuNCs becomes locally a new source of radiation emmiting high-energy electrons that will generate free radicals and ionizations demaging the cancer cells [40]. The results of this study were reproduced in several other investigations (squamous cell [41], brain [42], subcutaneous [40]) and did not reveal any toxicity of the phosphine-coated AuNCs.

\subsection{Thiolate-protected gold nanoclusters}

\subsubsection{Preparation}

A common approach for preparing AuNCs is to use thiols as surface-protecting ligands. The methodology is based on the observation that thiolate ligands can coordinate gold atoms and form gold-sulfur bonds with strength almost comparable to the covalent bond [43]. Additionally, it was observed that the structural and electronic properties of the resulting AuNCs are strongly influenced by the nature of the protecting ligands [44], as further discussed. Using Burst procedure [45], Ackerson et al. developed the synthesis of AuNCs with different water soluble thiols, $\mathrm{HAuCl}_{4}$ and $\mathrm{NaBH}_{4}$ [46]. The gold precursor $\left(\mathrm{HAuCl}_{4}\right)$ was mixed with the thiol in a 3:1/thiol:Au ratio in methanol/water (1:1) and the resulting complex was subsequently reduced by the addition of $\mathrm{NaBH}_{4}$ in excess. Among different tested organothiolates (36), the 4-mercaptobenzoic acid (p-MBA) exhibited a remarkable ability to produce AuNCs of extremely low polydispersity. The AuNCs were also easily purified by precipitation and were chemically stable for months. Highly uniform AuNCs of various sizes were then obtained by a comprehensive optimization of the ligand/Au(III) input ratio and methanol/water content [47-50][51]. Further characterizations revealed masses of 23, 51 and $88 \mathrm{kDa}$, sizes between 1.5 and $2.5 \mathrm{~nm}$ [48] and the X-ray structural analysis demonstrated that the $23 \mathrm{kDa}$ AuNCs was an $\mathrm{Au}_{102}(p-\mathrm{MBA})_{44}$ [50][52]. A MBA-protected $\mathrm{Au}_{144} \mathrm{NCs}$ was similarly prepared and characterized [53]. Remarkably, it was shown that the coordinating ligands at the surface of the AuNCs can be easily exchanged with free thiolates in aqueous solution at neutral $\mathrm{pH}$ and in a $\mathrm{SN}_{2}$-like mechanism [54]. This ligand-exchange property is extremely important and opens the possibility to prepare highly monodisperse AuNCs with further post-functionalization abilities. 


\subsubsection{Biological evaluations}

\section{Electron microscopy imaging}

The thiolate-protected AuNCs $\left(\mathrm{Au}_{102}\right.$ and $\left.\mathrm{Au}_{144}\right)$ were used as nanoprobes for imaging supramolecular structures in solution. They offered a better contrast in comparison to the Nanogold because the gold core is more substantial. Hakkinen and his coworkers reported the site-specific covalent conjugation of functionalized atomically mono-dispersed AuNCs with $1.5 \mathrm{~nm}$ metal core to viral surfaces of enteroviruses echovirus 1 (EV1) and coxsackieviras B3 (CVB3) [55]. Some benzoic acids of $\mathrm{Au}_{102}(\mathrm{pMBA})_{44}$ were reacted with a heterobifunctional spacer in order to equip the nanocluster with a maleimide group for further coupling reaction to free cysteines present on the surface of viral particles. Several AuNCs were covalently conjugated to EV1 and CVB3 and the resulting labeled viral particles were observed by TEM (Figure 2). Covalent attachements of the AuNCs on the viral particle did not appear to diminish the viral infectivity. This property permited to investigate the structure-function relationships of enteroviruses (in cellulo) and follows the onset of viral genome release (e.g. entry mechanism into cells and virus uncoating). It was latter demonstrated that a compound binding to the viral particle can also be linked to AuNCs and label its binding pocket onto the viral particle [56]. The approach offered new images on the sites of the enteroviruses EV1 and CVA9 where the compounds bound. Thiolate-protected AuNCs were also used to facilitate the characterization of a sophisticated protein delivery system as described by Postupalenko et al. [57]. An analogous AuNCs was also observed to be easily equipped with nuclear localization signal (NLS) and shuttled into the nuclei of living cells in a peptide-dependent manner without cell toxicity [58]. The results demonstrate that these AuNCs can be used inside the cell and open the way to other intracellular delivery opportunities.

\section{Drug, protein delivery}

Bowman et al. demonstrated that the $2 \mathrm{~nm}$ AuNCs having the exact formula $\mathrm{Au}_{144}\left(\mathrm{SC}_{6} \mathrm{H}_{4} \mathrm{COOH}\right)_{52}$ could transform a weakly binding and biologically inactive molecule into a multivalent conjugate that can inhibit HIV-1 fusion to human cells [59]. The $\mathrm{Au}_{144}\left(\mathrm{SC}_{6} \mathrm{H}_{4} \mathrm{COOH}\right)_{52}$ was conjugated to $\mathrm{SDC}-1721$ known as a CCR5 antagonist which functions as principal entry co-receptor for most commonly transmitted strains of HIV-1. The average number of SDC-1721 molecules per AuNCs was 12. The antiviral activity of AuNCsSDC-1721 was determined on phytohemagglutinin (PHA)-stimulated peripheral blood mononuclear cells (PBMCs) that were previously infected with the CCR5-targeting HIV-1 clone JR-CSF or JR-FL. The results showed that JR-CSF was less sensitive compared to JR- 
FL and proved as well that a therapeutically inactive monovalent small organic molecule coated with AuNCs can become an effective inhibitor of HIV fusion.

Rotello et al. reported a direct cytosolic delivery of CRISPR/Cas9 using nanoassemblies containing $2 \mathrm{~nm}$ AuNCs, Cas9 protein and sgRNA [60]. The prepared delivery nanosystem showed high delivery efficiency and acceded to selective gene editing. The same system was further used to knock out SIRP- $\alpha$ in macrophages to turn of the "don't eat me" signal triggering thus the phagocytosis of cancer cells [61]. These experimental observations/open the way to new immunotherapeutic strategies for cancer therapy.

\subsubsection{Biomedical prospects}

\section{Radiotherapy}

Zhang et al. reported that the gluthathione-coated AuNCs namely $\mathrm{Au}_{10-12}(\mathrm{GSH})_{10-12}$ was uptaken in larger amount by tumor cells than healthy tissues and evaluated their ability to sensitize tumor cells to gamma radiation [62]. The $\mathrm{Au}_{10-12}(\mathrm{GSH})_{10-12}$ were administered by intraperitoneal injection into U14 tumor-bearing mice and subsequently irradiated by gamma radiation. After 23 days, the $\mathrm{Au}_{10-12}(\mathrm{GSH})_{10-12}$ and radiation co-treated group displayed tumors with $57 \%$ decreased volume in comparison to the control groups (Figure 3a). To get further insights on the in vivo behavior of $\mathrm{Au}_{10-12}(\mathrm{GSH})_{10-12}$, the mice were analysed for gold content at $24 \mathrm{~h}$ and 23 days post injection (Figure 3b). The $\mathrm{Au}_{10-12}(\mathrm{GSH})_{10-12}$ clearly accumulated into the tumor at $24 \mathrm{~h}$ and were observed in most blood-accessible organs. At 23 days post-injection, the $\mathrm{Au}_{10-12}(\mathrm{GSH})_{10-12}$ were still present into the tumors but were cleared out from all other organs, indicating that they might be administrated on long term without risk and undesired accumulation in some tissues.

\section{In vivo toxicity and clearance}

The group of Feldheim performed in vivo toxicity, biodistribution and clearance studies of non-fluorescent AuNCs-GSH of $1.2 \pm 0.9 \mathrm{~nm}$ in mice following a subcutaneous administration at different concentrations [63]. No morbidity was observed even at the highest concentration of $60 \mu \mathrm{M}$ used in a 4 weeks-experiment. At lower concentrations (10 and $20 \mu \mathrm{M})$, AuNCs-GSH were rapidly cleared out from the body by kidney filtration but at increased concentration $(60 \mu \mathrm{M})$ the AuNCs-GSH were uptaken in part by the reticulo endothelial system (RES). Alltogether these data suggest that AuNCs-GSH can be indeed effectively cleared out from the body by glomerular filtration but that the pharmacokinetic profile becomes less straightforward when the blood starts to be saturated with these AuNCs. 
The group of Ackerson studied the ADME and PK properties of five well defined $\mathrm{Au}_{25}(\mathrm{SR})_{18}$ and $\mathrm{Au}_{102}(\mathrm{SR})_{44}$ nanoclusters with different SR ligand shells in a murine model [15]. Each AuNCs was prepared and protected with three different ligands: the as-synthesized ligand shell $\mathrm{Au}_{25}(\mathrm{GSH})_{18}, \mathrm{Au}_{102}(\mathrm{p}-\mathrm{MBA})_{44}$ and three partially ligand exchanged shells with tetraethylene glycol grafted in various amounts: $\mathrm{Au}_{25}(\mathrm{GSH})_{9}\left[\mathrm{~S}\left(\mathrm{CH}_{2}\right)_{6}(\mathrm{EG})_{4} \mathrm{OH}\right]_{9}$, $\mathrm{Au}_{25}(\mathrm{GSH})_{6}\left[\mathrm{~S}\left(\mathrm{CH}_{2}\right)_{6}(\mathrm{EG})_{4} \mathrm{OH}\right]_{12}$ and $\mathrm{Au}_{102}(\mathrm{pMBA})_{25}\left[\mathrm{~S}\left(\mathrm{CH}_{2}\right)_{11}(\mathrm{EG})_{4} \mathrm{OH}\right]_{19}$. After intravenous administration, the distribution and excretion properties were surveyed. The nature of the surface coating dramatically altered the biodistribution and excretion profile. For instance, the $\mathrm{Au}_{25}(\mathrm{GSH})_{18}$ accumulated more in the kidneys while those substituted with tetraethylene glycol accumulated in the liver and kidneys. The $A_{102}(\mathrm{p}-\mathrm{MBA})_{44}$ and $\mathrm{Au}_{102}(\mathrm{pMBA})_{25}\left[\mathrm{~S}\left(\mathrm{CH}_{2}\right)_{11}(\mathrm{EG})_{4} \mathrm{OH}\right]_{19}$ were primarly located in the liver and spleen following then a renal and hepatic excretion.

Rotello and coworkers analyzed the impact of the surface coating on the cellular uptake of $2 \mathrm{~nm}$ AuNCs [64]. The $2 \mathrm{~nm}$ AuNCs as well as $4 \mathrm{~nm}$ and $6 \mathrm{~nm}$ AuNPs-dodecanthiol were synthesized and then functionalized with anionic, zwitterionic and cationic head groups ligands by exchange place reaction. The cellular uptake performed in HeLa cells showed that the cationic head groups caused the most cellular internalization and the uptake increased as the size increased. For the anionic and zwitterionic AúNPs, the uptakes were moderate and decreased as the size increased. Thereafter, the same group has studied the in vivo distribution of AuNCs $(2 \mathrm{~nm})$ with cationic, neutral or anionic terminated head groups after i.v. administration into mice [65]. The neutral AuNCs were partially uptaken by the RES into the spleen and liver but were also excreted by the glomeruli. The anionic AuNCs were efficiently excreted by the glomeruli, whereas the cationic AuNCs were accumulating into the kidneys.

The impact of size on tiopronin-coated AuNCs during the cellular internalization pathway was also investigated by Huang et al. [66]. The $2 \mathrm{~nm}$ and $6 \mathrm{~nm}$ AuNCs-tiopronin were prepared according to the Murray's procedure [67][68]. A $15 \mathrm{~nm}$ AuNPs-tiopronin were prepared in parallel by reacting AuNPs-citrate with tiopronin. TEM analysis showed that $2 \mathrm{~nm}$ AuNCs-tiopronin generate higher cellular uptake in cancer cells than the other AuNPstiopronin. The in vivo pharmacokinetic and biodistribution studies were then examined after a single intravenous injection into tumor-bearing mice. The $2 \mathrm{~nm}$ and $6 \mathrm{~nm}$ AuNCs-tiopronin were observed to strongly accumulate into the tumor with little accumulation in any other organs. In contrast, the $15 \mathrm{~nm}$ AuNPs-tiopronin were detected in spleen and liver [67]. An additional work performed by Simpson et al. revealed that the $2.5 \mathrm{~nm}$ AuNCs-tiopronin unfortunately engendered harmful side effects in mice that were treated with concentrations 
above $20 \mu \mathrm{M}$ [69]. These harmful side effects were latter reduced by grafting PEG on the surface of AuNCs at a $10 \%$ ratio [70].

\section{Fluorescent gold nanoclusters}

Fluorescence microscopy is extremely important to the biomedical field and brings considerable help in deciphering the fundamental mechanisms of life. Generally, the fluorescent signal is produced after excitation of the emitter (e.g. AuNC, if its structure permits) that releases the photonic energy absorbed at a given excitation wavelength. It has been observed that AuNCs can become fluorescent and different synthetic strategies that directly affect the appearance and the quality of the emitted signal have been proposed (see below). Compared to non-fluorescent AuNCs that contain in their structure only the reduced form of gold as $\mathrm{Au}(0)$, for the fluorescent $\mathrm{AuNCs}$ the presence of residual $\mathrm{Au}(\mathrm{I})$ atoms on the surface of the cluster containing $\mathrm{Au}(0)$ is determinant in displaying fluorescent properties. It is generally accepted that the electronic transition at the origin of the fluorescence is due to $\mathrm{Au}(\mathrm{I})$ complexes that exists as $-\mathrm{S}-\mathrm{Au}(\mathrm{I})-\mathrm{S}-\mathrm{Au}(\mathrm{I})-\mathrm{S}-$ staple surface shell surrounding the reduced core gold $\mathrm{Au}(0)$. In fact, both $\mathrm{Au}(\mathrm{I})$ and anchoring ligands are involved in the electronic transitions yielding a fluorescence that is specific to each combination of ligand/AuNC. $\mathrm{Au}(\mathrm{I})$ complexed with phosphorus- sulfur- or nitrogen-containing ligands are generally present on the surface of AuNCs but their structure, length and stability can dramatically vary [71]. Some AuNCs will consequently be fluorescent, some not and other will have fluorescence that/vary according to the environment change. A deeper understanding of $\mathrm{Au}(\mathrm{I})$ complex physicochemical behavior remains to be achieved. Models explaining fluorescence of some AuNCs are reviewed in the following paragraphs.

\subsection{Thiolate-protected gold nanoclusters}

\subsubsection{Preparation}

Fluorescent AuNCs were observed during the synthesis of AuNCs using a bidendate anchoring disulfide (e.g. single lipoic acid (LA) or multiple dihydrolipoic acid (DHLA)) linked to polyethyleneglycol [72,73]. Some AuNCs displayed photoluminescent emission in far red region with good quantum yields (QYs) [73]. The Mattoussi group further developed a straightforward approach without $\mathrm{NaBH}_{4}$ for the synthesis of fluorescent AuNCs of different emitting colors (yellow, red or blue) [74]. In their approach, the ligands LA-PEG-OCH ${ }_{3}$ or LA-PEG-NH$H_{2}$ were firstly UV-irradiated at $350 \mathrm{~nm}$ and then mixed with $\mathrm{HAuCl}_{4}$ in alkaline medium $(\mathrm{pH}=11)$ as shown in Figure 4. A yellow emitting AuNCs were obtained after only 
$2 \mathrm{~h}$ of reflux. Extended reaction time at $100^{\circ} \mathrm{C}$ led to the formation of blue or red emitting AuNCs. It was observed that the yellow emitting AuNCs had smaller diameters than blueand red-emitting AuNCs [74]. Sun et al. synthesized near infrared (NIR) fluorescent MUAprotected AuNCs using 11-mercaptoundecanoic acid (MUA) as reducing agent and coordinating ligand in an one-pot protocol involving $20 \mathrm{~h}$ of stirring [75]. Xu et al. further developed a "dual-ligand" co-functionalized orange-red fluorescent $\operatorname{AuNCs}\left(\lambda_{\mathrm{em}}=608 \mathrm{~nm}\right)$ [76]. The synthesis consisted in the addition of $\mathrm{NaOH}$ to a solution containing MUA followed by the addition of $\mathrm{HAuCl}_{4}$ and methionine (Met), both at room temperature. The reaction was completed in $2 \mathrm{~h}$ at room temperature without stirring. Yaun et al. reported the preparation of $\mathrm{Au}_{25} \mathrm{NCs}$ protected by negatively charged thiolate ligands collocating with positively or neutrally charged thiolate ligands via $\mathrm{NaOH}$ mediated $\mathrm{NaBH}_{4}$-reduction method [77]. These AuNCs exhibited unexpected dual absorption at 780 and $980 \mathrm{~nm}$ likely due to the mixing of two ligands with different charges $\left(-\mathrm{COO}^{-},-\mathrm{NH}_{3}{ }^{+}\right.$or $\left.-\mathrm{OH}\right)$ onto the surface of AuNCs that introduced an anisotropy. In another study, Liu et al. reported the preparation of fluorescent water-soluble AuNCs by firstly reducing $\mathrm{HAuCl}_{4}$ with $\mathrm{DMF}$ at $140^{\circ} \mathrm{C}$ and then capping the nanocluster with thiols or disulfide-containing molecules (e.g. MUA, thioctic acid TA, 1dodecanthiol DT, etc.) [78]. These capped-AuNCs revealed photoluminescence abilities. They displayed a ligand-concentration dependent behavior in the emission spectra and exhibited QYs of 5\% to $8 \%$.

Zhang et al. elaborated a simple one-pot method for preparing water-soluble ultra-stable and multifunctional AuNCs [79]. Various ligand-coated AuNCs were obtained with sizes varying between 1.4 to $1.8 \mathrm{~nm}$. The method consists in using a " $\mathrm{HS}-\mathrm{C}_{11}-\mathrm{EG}_{6}-\mathrm{X}$ "-like molecule as ligand bearing a thiol group ( $\mathrm{SH})$, an alkyl chain (C11), an hexethyleneglycol $\left(\mathrm{EG}_{6}\right)$, and a functional group $\mathrm{X}=\mathrm{OH}, \mathrm{COOH}, \mathrm{NH}_{2}, \mathrm{GRGD}$, etc. Two synthetic procedures were assessed. In a first procedure, an AuNCs precursor was prepared by mixing $\mathrm{HAuCl}_{4}$ with histidine and after $2 \mathrm{~h}$ of incubation, the $\mathrm{HS}-\mathrm{C}_{11}-\mathrm{EG}_{6}-\mathrm{X}$ was added to the synthetic precursors. In a second procedure, $\mathrm{HAuCl}_{4}$, histidine and $\mathrm{HS}-\mathrm{C}_{11}-\mathrm{EG}_{6}-\mathrm{OH}$ were mixed in an one-pot reaction. The comparison of results indicated that the two procedures yielded AuNCs of similar sizes (1.42 $\mathrm{nm}$ vs. $1.65 \mathrm{~nm})$, morphology and fluorescence emission properties. However, the AunCs that were prepared using the sequential procedure, had higher QYs than the one prepared via the one-pot reaction.

\subsubsection{Biological evaluations}

\section{In vitro drug delivery}


The ability of AuNCs to deliver an antitumoral drug (Doxorubicin, DOX) was studied [79]. The AuNCs capped with $\mathrm{HS}-\mathrm{C}_{11}-\mathrm{EG}_{6}-\mathrm{OCH}_{2} \mathrm{COOH}$ and $\mathrm{HS}-\mathrm{C}_{11}-\mathrm{EG}_{6}-\mathrm{OH}$ at a $1: 2$ ratio were covalently linked to DOX using an EDC/sulfo-NHS coupling reaction. Before conjugation, the AuNCs did not display any absorbance at wavelengths $>400 \mathrm{~nm}$, while after coupling, the new AuNCs-DOX displayed a maximum excitation peak at $475 \mathrm{~nm}$. Confocal imaging of experiments performed on A549 cell line with $1 \mu \mathrm{g} / \mathrm{ml}$ DOX or AuNCs-DOX showed that red dots were mainly found inside the cell after $1 \mathrm{~h}$ of incubation. After $3 \mathrm{~h}$ of incubation, the red fluorescent dots were increased in number in the cytoplasm and could also be found into the cell nuclei. Chatterjee et al. prepared fluorescent AuNCs using deoxy guanosine 5'-triphosphate (dGTP) as protecting ligand [80]. The generated orange fluorescent AuNCs-DGTP of $2 \mathrm{~nm}\left(\lambda_{\mathrm{ex}}=325 \mathrm{~nm}, \lambda_{\mathrm{em}}=590 \mathrm{~nm}, \mathrm{QY}=2.16 \%\right)$ were able to encapsulate an anticancerous drug (cis-platin, $\mathrm{Pt}$ ) and the resulting nanodelivery system was further coated with PEG. When delivered to HeLa cells, the AuNCs-DGTP-Pt-PEG could be tracked within the cells using the fluorescence of AuNCs and were observed to induce cell apoptosis due to cis-platin delivery.

\subsubsection{Biomedical prospects}

\section{In vitro immune response}

Fernandez et al. have studied the effects of fluorescent AuNCs-(Zw, ZwMUA and $\mathrm{mPEG}$ ) on the intracellular accumulation and immune response of human derived-monocyte dendritic cells (DCs) [81]. The/study demonstrated that the cellular uptake of AuNCs bearing zwitterionic ligands was more effective than PEGylated ones. The group also compared these AuNCs to AuNPs $(12 \mathrm{~nm})$ bearing the same type of ligands. The results showed that AuNCs$\mathrm{Zw}$ induced low cytotoxicity and strong immunosupressive response (Th1/Treg pattern) associated with DC maturation state whereas AuNPs-Zw provoked a cytotoxic response, involving Natural Killer cells (CD56).

\subsection{Peptide-protected gold nanoclusters}

\subsubsection{Glutathione-protected gold nanoclusters}

\subsubsection{Preparation}

The tripeptide GSH is a popular ligand for synthesizing AuNCs with well-defined morphologies. Additionally, GSH plays an important role in the cell metabolism by keeping the cellular potential in a reduced state. Schaaff et al. have developed a synthetic approach that led to the preparation of $\mathrm{Au}_{25}(\mathrm{GSH})_{18}$ nanoclusters [82]. In this method GSH was 
solubilized in water, mixed with a methanolic solution of $\mathrm{HAuCl}_{4}$ then 15 min later with an aqueous solution of $\mathrm{NaBH}_{4}$. Negishi et al. produced several series of $\mathrm{AuGSH}_{\mathrm{n}}(\mathrm{n}=10-39)$ of various sizes and masses [83]. The group demonstrated by PAGE analysis and ESI mass spectroscopy that the most stable AuNCs was $\mathrm{Au}_{25}(\mathrm{GSH})_{18}(10437 \mathrm{Da})$. The strong stability of $\mathrm{Au}_{25}(\mathrm{GSH})_{18}$ was explained by the mechanism of thiolate-induced stabilization that implies a preferential formation of a specific type of AuNCs. Moreover, a selective stabilization of certain $\mathrm{AuGSH}_{\mathrm{n}}$ involves an electron donation from Au core to GSH ligands shell but with a smaller impact compared to $\mathrm{Au}(\mathrm{I})$-thiolate complexes.

Luo et al. developed strong fluorescent orange-emitting AuNCs using GSH as ligand [13]. The synthesis was straightforward and consisted in mixing aqueous solutions of GSH and $\mathrm{HAuCl}_{4}$ heated at $70^{\circ} \mathrm{C}$ for $24 \mathrm{~h}$. The $\mathrm{GSH}$ is the "reducing-cum-protecting" reactant meaning that GSH is used both as a reducing and protecting ligand of the generated AuNCs. It was observed that the physicochemical properties of the resulting AuNCs heavily rely on the reaction temperature and the GSH/Au input ratio. Indeed, the preparation of fluorescent $\mathrm{Au}(\mathrm{GSH})_{\mathrm{n}}$ is a multi-step process that involves 3 main phases. The first phase is the reduction of $\mathrm{Au}(\mathrm{III})$ to $\mathrm{Au}(\mathrm{I})$ by the sulfur of GSH (or GSSG) and a concomittant formation of $\mathrm{Au}(\mathrm{I})$ thiolate or $\mathrm{Au}(\mathrm{I})-\mathrm{X}$ complexes (where $\mathrm{X}=$ non-thiolate ligand). The second phase consists in the selective reduction of $\mathrm{Au}(\mathrm{I})-\mathrm{X}$ complexes to $\mathrm{Au}(0)$ atoms and caging of the $\mathrm{Au}(0)$ core by $\mathrm{Au}(\mathrm{I})$-thiolate complexes. The reduction of $\mathrm{Au}(\mathrm{I})-\mathrm{X}$ complexes to $\mathrm{Au}(0)$ can also be performed using GSSG at $70^{\circ} \mathrm{C}$. In the third phase, an aggregation of $\mathrm{Au}(0)$-on- $\mathrm{Au}(\mathrm{I})$-thiolate occurs. Further characterization indicated that the photoluminescence originated from the $\mathrm{Au}(\mathrm{I})-\mathrm{GSH}$ complexes [13].

$\mathrm{Wu}$ et al. studied the photoluminescent properties of $\left[\mathrm{Au}_{25} \mathrm{GSH}_{18}\right]^{\mathrm{q}}$ where $q$ is the charge of the cluster and provided evidences that the photoluminescent properties originated from $\mathrm{Au}(\mathrm{I})$-thiolate complexes [84]. They were also able to set up general rules for tailoring the photoluminescent properties of AuNCs by increasing the electron donating capacity of the ligand via modification of the ligand's structure and by increasing the electro-positivity of the metal core for AuNCs to sustain multiple charge states.

\subsubsection{Biological evaluations \\ In vitro fluorescence imaging}

Photoluminescent AuNCs-GSH were prepared by Polavarapu et al. following a modified approach inspired by Murray's work [85]. The obtained AuNCs-GSH revealed a diameter of approx. $1.1 \mathrm{~nm}$ that corresponds to about 25 gold atoms cluster and showed high 
photo-stability as well as strong two-photon excitation photoluminescence properties in living cells [86]. The AuNCs-GSH did not induce apparent cytotoxicity even at $400 \mu \mathrm{g} \mathrm{ml}^{-1}$ concentrations for human neuroblastoma cancer (SH-SY5Y) cells. The two-photon excitation fluorescence image of the SH-SY5Y cells incubated with AuNCs-GSH under excitation of femtosecond laser pulses at $800 \mathrm{~nm}$ proofed that the AuNCs-GSH were entering into cells.

\subsubsection{Biomedical prospects}

\section{Photodynamic therapy}

AuNCs can convert the absorbed light into heat. This energy transfer ability is utilized in photodynamic therapy (PDT), a non-invasive strategy that involves the use of a photosensitizer and external light [87]. Red-emitting AuNCs-GSH with QY of 5.8\% were prepared using tetrabutylammonium borohydride (TBAB) as reducing agent [88]. The amino groups of GSH were then covalently functionalized with an activated folic acid- $\mathrm{PEG}_{2000}$ $\left(\mathrm{PEG}_{2 \mathrm{~K}}-\mathrm{FA}\right)$ to equip the fluorescent AuNCs-GSH with a cell surface receptor targeting moiety (FA), a furtive layer $\left(\mathrm{PEG}_{2 \mathrm{~K}}\right)$ and then a photosensitizer (Chlorin e6, Ce6) [89]. Due to its structure, Ce6-AuNCs-GSH-PEG $2 \mathrm{~K}-\mathrm{FA}$ could perform selective targeting of tumors in combination with PDT. The targeting efficacy was then tested using MGC-803, a gastric cancer cell line that overexpress FA receptors. The fate of the Ce6-AuNCs- $\mathrm{PEG}_{2 \mathrm{~K}}-\mathrm{FA}$ was tracked using their intrinsic fluorescence by confocal laser scanning microscopy (CLSM) and flow cytometry (FCM). The Ce6-AuNCs-PEG $\mathrm{PK}_{2 \mathrm{~K}}-\mathrm{FA}$ showed excellent biocompatibility and revealed its photosensitizing and cell killing abilities upon laser irradiation. The in vivo PDT potential of the Ce6-AuNCs-PEG $2 \mathrm{~K}-\mathrm{FA}$ was next confirmed on MGC-803 tumor bearing mice during a 21 days experiment. The same group has recently reported the conjugation of an antibody targeting the CD3 receptors onto red-emitting AuNCs-GSH and investigated the performance of such Ce6-loaded system for PDT in mice model [90]. The results confirmed that photodynamic and immunotherapy actions can be combined for improved therapeutical activity in mice model.

\section{In vivo delivery and fluorescence imaging}

The capacity of AuNCs to deliver into cells hybrid mixtures of protein and nucleic acids has been reported by Wang et al. [91]. A multifunctional nanosystem containing AuNCs has been employed for CRISP/Cas9 protein delivery and targeted gene editing (single guide RNA, sgRNA). Fluorescent AuNCs were firstly prepared by reducing Au(III) with GSH. Some surface-bound GSH were then substituted with a thiolated-TAT peptide to decorate the 
nanosystem with transduction domains [92]. The positively charged TAT-AuNCs were next associated to negatively charged Cas9 protein and sgRNA-coding DNA plasmid to form a ternary [TAT-AuNCs/Cas9 protein/DNA] complex named GCP. Since the GCP was made with excess DNA plasmid, its overall charge was negative. Thus, for enhanced uptake into cells, the ternary complex was further protected with a polyethylene glycol-phospholipid layer forming a LGCP nanosystem. Further on, the experiments using fluorescently labeled DNA plasmid showed indeed that this nanosystem was uptaken by the A375 cells. To demonstrate the cytosolic release and trafficking of the Cas9/DNA plasmid into the nucleus, in vivo experiments were performed on mice grafted with tumors. The LGCP was delivered to the subcutaneous tumor by intratumoral injection aiming to destruct the polo-like kinase I (PLK-1) gene. At 16 days postinjection it was observed that the LGCP diminished the production of PLK-1 ( $>70 \%$ down-regulation) resulting in inhibition of the tumor growth by $75 \%$ in mice.

Another system that combines intracellular delivery with fluorescent detection property was developed by crosslinking AuNCs-GSH with cationic polymers such as poly(allyl amine hydrochloride) (PAH) or polyethylenimine (PEI). The crosslinking yielded nanogels with $\mathrm{pH}-$ dependent swelling properties and a 3 to 4 -fold fluorescent enhancement due to aggregationinduced emission (AIE) (Figure 5a) [93]. The nanogels were loaded with peptides (2 kDa) or antibodies $(\mathrm{IgG} ; 150 \mathrm{kDa})$ giving rise to protein delivery nanosystems that could be tracked using various imaging technics (electron and fluorescence intensity; life time microscopy) as well as flow cytometry (Figure 5 b).

\subsubsection{Other synthetic peptides protected-gold nanoclusters}

\subsubsection{Biological evaluations}

Detection of the nuclei of living cells is highly important in imaging analysis. To selectively label the nucleus, a peptide $\mathrm{H}_{2} \mathrm{~N}-\mathrm{CCYRGRKKRRQRRR} \mathrm{was} \mathrm{designed} \mathrm{to} \mathrm{contain}$ two different sequences in its structure. The first sequence (CCY) had the role in facilitating the AuNCs nucleation and the other one (RGRKKRRQRRR) was responsible for the transduction and nuclear accumulating properties as constituted from a nuclear localization signal (NLS) derived from protein HIV-1 (TAT) (Figure 6) [92][94]. After synthesis, the AuNCs-CCYTAT were incubated with three different cell lines: HeLa, GES-1 (human gastric mucosa cell) and MRC-5 (human embryonic lung fibroblast cells). The results showed that the AuNCs-CCYTAT were accumulating into the nuclei of cells but with efficiency that varies function of the cell type. Following a similar synthetic procedure, Liu et al. fused the 
CCY sequence to the SV40 NLS sequence to obtain a tridecapeptide (CCYGGPKKKRKVG) that could lead to a fluorescent $\mathrm{AuNCs}$, which was assigned $\mathrm{Au}_{25} \mathrm{NCs}$ formula according to its photoluminescent properties and MS spectrum [95]. When incubated with cells, the fluorescent $\mathrm{Au}_{25} \mathrm{NCs}$-tridecapeptides $(\lambda=645 \mathrm{~nm})$ was observed in perinuclear compartments and caused cell death. The cell death was explained from the propention of $\mathrm{Au}_{25} \mathrm{NCs}$ tridecapeptide to associate to TrxR1, suppressing its activity in the cytoplasm. This leads to an increased level of reactive oxygen species (ROS) that induces the up-regulation of the activated poly(ADP-ribose) polymerase (PARP) which allows the tumor cell apoptosis to take place in an Au dose dependent manner (Figure 7).

De la Rica et al. designed AuNCs-peptides with emission in the NIR region [96]. The employed peptide was synthesized as $\mathrm{C}(\mathrm{GRP})_{3}$ and used as a "template-ligand" yielding AuNCs-C(GRP) $)_{3}$. The resulting AuNCs-C(GRP) $)_{3}$ revealed an emission peak at $680 \mathrm{~nm}\left(\lambda_{\mathrm{ex}}=\right.$ $440 \mathrm{~nm}$ ). In agreement with MALDI-TOF MS and PAGE analysis, it was concluded that the AuNCs had the $\mathrm{Au}_{16}-\mathrm{C}(\mathrm{GRP})_{3}$ formula. When added to human primary fibroblast cells, these $\mathrm{Au}_{16}-\mathrm{C}(\mathrm{GRP})_{3}$ were detected using their NIR emission properties by confocal microscopy. Additionally, $\mathrm{Au}_{16}-\mathrm{C}(\mathrm{GRP})_{3}$ did not induce acute toxicity up to $1 \mathrm{mg} / \mathrm{mL}$ but started to accumulate inside subcellular compartments.

\subsection{Amine protected-gold nanoclusters}

\subsubsection{Preparation}

D-penicillamine (D-PA) was used to prepare AuNCs with fluorescent properties $\left(\lambda_{\mathrm{ex}}=\right.$ $400 \mathrm{~nm}, \lambda_{\mathrm{ex}}=610 \mathrm{~nm}$ ) and good colloidal stability in aqueous media over the physiological $\mathrm{pH}$ range of 5-9 [97]. When incubated with living HeLa cells, the fluorescent AuNCs-DPA $\left(300 \mu \mathrm{g} \mathrm{ml}^{-1}\right)$ were observed to remain attached to the plasma membrane and get internalized into intracellular vesicles without promoting apparent cytotoxity. In a different study, Yang et al. synthesized AuNCs protected with chiral and racemic penicillamines (L, D, DL-PA) [98]. The AuNCs-L-PA and AuNCs-D-PA had strong fluorescence emission at $630 \mathrm{~nm}\left(\lambda_{\mathrm{ex}}=410\right.$ $\mathrm{nm}$ ) but different quantum yields (QY of 1\% and 5.4\% for AuNCs-L-PA and AuNCs-D-PA, respectively). The AuNCs-DL-PA did not display any fluorescence. Difference in behavior was also observed after addition to living HeLa cells. Chiral AuNCs-D-PA-and AuNCs-L-PA were highly cytotoxic at concentrations above $80 \mu \mathrm{M}$ in HeLa whereas the racemic AuNCsDL-PA was apparently not toxic at this dose.

Yang et al. described the preparation of water-soluble $\mathrm{Au}_{10} \mathrm{NCs}$ with bluish-greenemitting fluorescence by mixing $\mathrm{HAuCl}_{4}$ with histidine in water at room temperature without 
any reducing agents other than histidine [99]. The resulting aqueous solution of $\mathrm{Au}_{10} \mathrm{NCs}$ emitted a bluish green fluorescence $(490 \mathrm{~nm})$ under UV irradiation $(365 \mathrm{~nm})$. A similar onepot strategy using L-proline instead of histidine led to water-soluble and light-blue emitting AuNCs [100]. Other natural products were used to obtain AuNCs. Venkatesh et al. reacted 8mercapto-9-propyladenine with $\mathrm{HAuCl}_{4}$ yielding fluorescent AuNCs that could be used to stain cell nuclei of living cells [101].

Fluorescent AuNCs were also prepared by mixing gold(III) chloride with aqueous solutions containing MES or HEPES [102]. In contrast to former reactions, the production of AuNCs was extremely slow. Non-fluorescent complexes were initially obtained and then gradually transformed (a matter of several days) into fluorescent AuNCs. The AuNCs-HEPES exhibited emission at $500 \mathrm{~nm}$ and the AuNCs-MES at $485 \mathrm{~nm}$. Other small molecules could lead to the formation of similar AuNCs and their fluorescence was stable at room temperature for almost 6 months. This strategy holds the potential for designing capping ligands for fluorescent AuNCs that can be directly linked to biological molecules.

\subsubsection{Biomedical prospects}

\section{In vivo fluorescence imaging}

Chen et al. developed AuNCs with high bluish-green fluorescence (480 nm) using histidine as reducing and coordinating ligand [103]. The resulting AuNCs-His of $1.4 \mathrm{~nm}$ size were obtained after 5 days of stirring at $4^{\circ} \mathrm{C}$. Since the $480 \mathrm{~nm}$ wavelength does not penetrate deeply into tissue, the AuNCs-His were further equipped with a NIR organic dye (MPA) [104]. Using this novel nanoprobe, it was possible to track the biodistribution of AuNCs-HisMPA by NIR fluorescence imaging in tumor bearing nude mice model (MCF 7). The authors showed that the in vivo retention time of AuNCs-His-MPA was enhanced in comparison to NIR dye alone, observation that gives the opportunity to perform real-time monitoring of tumors in living animals.

A core-hollow and shell-porous poly(acrylic acid) nanogel (PAA) was used as template for in situ reduction of gold salts in aqueous enviroment followed by nucleation and growth of AuNCs of $1.7 \mathrm{~nm}$ [105]. The generated AuNCs-PAA-Ngs displayed intense fluorescence at $825 \mathrm{~nm}$ and good properties for in vivo imaging with deep penetration. The nanogel was subcutaneously injected into healthy mouse to track the fluorescence $\left(\lambda_{\mathrm{ex}}=704 \mathrm{~nm}, \lambda_{\mathrm{em}}=745\right.$ $\mathrm{nm}$ ) in the subcutaneous tissue under NIR excitation. Since bright fluorescence has been observed, further experiments were performed on subcutaneous hepatic H22 tumor-bearing mice. A first fluorescence signal was registered 10 min postinjection that was correlated with 
good fluorescence contrast distinguishing thus the tumor from surrounding tissues. An accumulation of AuNCs-PAA-Ngs took place in different organs mainly liver and spleen but the organs were considerably cleared out within $96 \mathrm{~h}$ postinjection.

\subsection{DNA protected-gold nanoclusters}

\subsubsection{Preparation}

DNA, or more specifically oligonucleotides were also grafted onto AuNCs and found biomedical applications [106]. Most of them displayed sizes larger than $2 \mathrm{~nm}$ and thus cannot be considered as nanoclusters. Some of AuNPs-DNA exhibits fluorescence abilities due to the presence of cytosine-rich motifs. This feature is intensively used for the preparation of a large range of sensor nanoprobes. Excellent reviews on their synthesis, characterization and applications are available [107][108][109]. Attempts to prepare AuNCs (size below $2 \mathrm{~nm}$ ) equipped with DNA were rare. Zhu et al. prepared fluorescent $\mathrm{Au}_{8} \mathrm{NCs}-\mathrm{DNA}$ using double stranded DNA and a sonication method [110]. Kennedy et al. reported the preparation of blue fluorescent DNA-AuNCs from single-strended 30-mer DNA homopolymers using citrate as reducing agent [111]. It was observed that poly-cytosine $\left(\mathrm{C}_{30}\right)$ DNA yields fluorescent nanoclusters only at low $\mathrm{pH}$ and in the presence of excess of DNA whereas poly-adenine $\left(\mathrm{A}_{30}\right)$ produces fluorescence at neutral $\mathrm{pH}$ with an adenine/Au ratio of 1:1. Li et al. reported the preparation of red fluorescent DNA-AuNCs using single-strended 23-mer DNA and dimethylamine borane as reducing agent [112]. Further on, fluorescent DNA-AuNCs were prepared using different hairpin DNAs and their fluorescence was influenced by the harpin loop [113]. Hosseini et al. prepared DNA-AuNCs for the detection of miRNA-21 [114]. The synthesis of the DNA-AuNCs was performed with both single and double-stranded DNAs. Single-strand DNAs were more effective in producing DNA-AuNCs due to the chemical reduction method. These DNA-AuNCs were also able to sense mi-RNA 21 and produced an increased fluorescence upon hybridation.

\subsection{Proteins-protected gold nanoclusters}

\subsubsection{Preparation}

Several proteins are effective templates to trigger complexation and nucleation of gold ions subsequently generating proteins containing AuNCs. It is important to point out that these proteins-AuNCs comprise only a small fraction of gold atoms and conserve their biocompatibility. In this process of biomineralization, the folding of the proteins and the peptidic sequence play a major role in the physicochemical properties of the AuNCs. Up to 
now, proteins like bovine serum albumin [115], human serum albumin [116], lysozyme [117], transferrin [118], lactoferrin [119], trypsin [120], pepsin [121], insulin [122], horseradish peroxidase [123] and few others that will further be discussed, have been reported to yield fluorescent proteins-AuNCs. Since the three-dimensional folding is important to protein structure and function, the reactions conditions were tailored according to the characteristics of employed proteins (solubility, stability in solution, pI, etc.). The mechanism leading to the formation of AuNCs within proteins remains uncertain. The formation and stabilization of proteins-AuNCs found only partial responses that had been experimentally obtained with several protein models. It was suggested that the immobilization of proteins on AuNCs takes place through the formation of a gold-thiol bond between AuNCs and cysteine or cysteine residues displayed on the surface of a protein [124]. In addition, AuNCs can also be stabilized by the nearby amino acids through non-covalent interactions [125]. Nevertheless, proteins without cysteine on their surface interact through a non-covalent interaction with AuNCs. The breaking of disulfide bonds facilitates the growth of the nanocluster and the stability of AuNCs in the protein environment is accomplished through the formation of $-\mathrm{S}-\mathrm{Au}(\mathrm{I})-\mathrm{S}-$ $\mathrm{Au}(\mathrm{I})-\mathrm{S}-$ staple that is at the origin of the fluorescence or through Au-S bonds between cysteine and $\mathrm{Au}$ atoms as well as by the non-covalent interactions with the surrounding amino acids [115][124]. However, if used wittingly, proteins template AuNCs during the nucleation step and subsequently reduce, stabilize and further encapsulate these growing AuNCs in a specific sort of arrangement likely as protein-AuNCs adduct.

Generally, proteins-AuNCs are synthetized in one or two-step reaction approach. The first one-pot reported method dates back from 2009 [115]. Briefly, aqueous solutions of $\mathrm{HAuCl}_{4}$ and $\mathrm{BSA}$ were mixed at $37^{\circ} \mathrm{C}$ and 2 min later $1 \mathrm{M}$ of $\mathrm{NaOH}$ was poured to the mixture. The reaction was stirred at $37^{\circ} \mathrm{C}$ for another $12 \mathrm{~h}$. The resulting BSA-AuNCs displayed red fluorescence $\left(\lambda_{\mathrm{ex}}=490 \mathrm{~nm}, \lambda_{\mathrm{em}}=640 \mathrm{~nm}\right)$ and a QY of $6 \%$. Further on, Zhang et al. reported an optimized synthesis for red fluorescent BSA-AuNCs $\left(\lambda_{\mathrm{ex}}=490 \mathrm{~nm}, \lambda_{\mathrm{em}}=\right.$ $640 \mathrm{~nm}$ ) by performing the same reaction at $80^{\circ} \mathrm{C}$ for only 10 min instead of $37^{\circ} \mathrm{C}$ for $12 \mathrm{~h}$ [126]. It was suggested that the high temperature favor the interactions between the gold ions and the amino acids side chains. A drawback resides in the high probability of a thermal denaturation of the protein folding. $\mathrm{Xu}$ et al. investigated the relation between the photoluminescence properties of the proteins-AuNCs, the nature and compositon of the initial proteins using BSA, lysozyme, trypsin and pepsin as protein models [127]. The content in lysine, tyrosine and tryptophan was determinant for the formation of fluorescent proteinsAuNCs. $\mathrm{Xu}$ et al. proposed that the amino group is involved in the initial binding and 
reduction of $\mathrm{Au}(\mathrm{III})$ to $\mathrm{Au}(\mathrm{I})$ near $\mathrm{pH}$ 7.0. It is only at $\mathrm{pH}>10$ that the tyrosine or tryptophan residues yielded to reduction of $\mathrm{Au}(\mathrm{I})$ to metallic $\mathrm{Au}(0)$ [127]. For $\mathrm{BSA}$, which contains 35 cysteines, its fluorescent ability was atributed to the formation of $\mathrm{Au}_{25} \mathrm{NCs}$. This $\mathrm{Au}_{25} \mathrm{NCs}$ was further described as $\mathrm{Au}_{13}(0)$ core surrounded by six $-\mathrm{S}-\mathrm{Au}(\mathrm{I})-\mathrm{S}-\mathrm{Au}(\mathrm{I})-\mathrm{S}-$ staple surface motifs.

Pepsin-AuNCs with blue, green, or red fluorescent emission were reported to be pHdependent as shown by Kawasaki et al. (Figure 8) [121]. The pepsin-Au ${ }_{25} \mathrm{NCs}$ with red fluorescence emission were obtained at $\mathrm{pH} 12$, the pepsin- $\mathrm{Au}_{13} \mathrm{NCs}$ (green fluorescence emission) were obtained under strong acid conditions at $\mathrm{pH} 1$ and the pepsin- $\mathrm{Au}_{5} \mathrm{NCs}$ as well as $\mathrm{Au}_{8} \mathrm{NCs}$ (blue fluorescence emission) were produced under alkaline conditions at $\mathrm{pH} 9$. Their fluorescence efficiencies (QYs of 3.7, 5.0 and 3.5\% for blue, green, and red) appeared better than the GSH-Au ${ }_{25} \mathrm{NCs}(\mathrm{QY} \approx 0.1 \%)$ and comparable to the $\mathrm{BSA}-\mathrm{Au}_{25} \mathrm{NCs}(\mathrm{QY} \approx 6 \%)$. The pepsin- $\mathrm{Au}_{25} \mathrm{NCs}$ and pepsin- $\mathrm{Au}_{13} \mathrm{NCs}$ were less sensitive to photo bleaching than the pepsin- $\mathrm{Au}_{5} \mathrm{NCs}$. When the solution of pepsin- $\mathrm{Au}_{25} \mathrm{NCs}$ was analyzed by TEM, 1-2 nm sizes were observed. In contrast, the other structures based on pepsin- $\mathrm{Au}_{13} \mathrm{NCs},-\mathrm{Au}_{5} \mathrm{NCs}$ and $-\mathrm{Au}_{8} \mathrm{NCs}$ were not detectable due to their sub-nanometer size. High-angle annular dark field scanning TEM (HAADF-STEM) image could confirm their presence fact that can also be used for further biological labeling. Chen et al. reported a straightforward one-pot approach to prepare high blue-fluorescence emitting lysozyme-Au $\mathrm{Al}_{8} \mathrm{NCs}(\lambda=455 \mathrm{~nm}$; QY $\approx 56 \%)$ by reacting an $\mathrm{Au}(\mathrm{III})$ precursor solution with lysozyme type VI (Lys VI) at pH 3 [128]. This Lys VI-Au $\mathrm{Al}_{8} \mathrm{NCs}$ could be further used as an intermediate for the preparation of Lys- $\mathrm{Au}_{25} \mathrm{NCs}$ by adjusting the $\mathrm{pH}$ to 12 . Further investigations regarding the interactions of AuNCs and Lys that can affect the properties of Lyz-AuNCs were reported by Mudedle et al. [124].

Wang et al. were the first to report the in situ biosynthesis of AuNCs by incubating micromolar solutions of $\mathrm{Au}(\mathrm{HI})$ with two different cancerous cell lines (HepG2, human hepatocarcinoma and K562, leukemia) [129]. The intracellular proteins bind and stabilize the resulting AuNCs, in effect concealing them with endogenous proteins. The results showed that the obtained AuNCs displayed the same fluorescence as AuNCs prepared by other synthetic routes (discussed earlier in this review) providing thus novel opportunities for in vitro imaging (e.g. intracellular fluorescent markers). Following a similar strategy, West et al. demonstrated the direct in situ biomineralization of AuNCs in non-tumorigenic neuronal microglial line C8B4 [130]. The reaction was observed to take place $24 \mathrm{~h}$ after the addition of $\mathrm{HAuCl}_{4}$ and was completed after $48 \mathrm{~h}$. The in situ obtained AuNCs were stabilized by 
intracellular proteins and revealed green fluorescence. These intracellular proteins containingAuNCs could be used as in situ fluorescent nanoprobes for biolabeling applications.

\subsubsection{Biological evaluations}

\section{In vitro delivery and fluorescent imaging}

Kong et al. synthesized bovine pancreatic ribonuclease A (RNAse A)-AuNCs for cancer imaging applications [131]. The resulting RNAse A-AuNCs displayed a fluorescence emission in the NIR range $\left(\lambda_{\mathrm{em}}=682 \mathrm{~nm}\right)$ with a good QY $\approx 12 \%$, a long fluorescence time $(\approx 1.5 \mu \mathrm{s})$ and a large Stokes shift $(\approx 210 \mathrm{~nm})$. When observed by TEM, the solution contained $1.6 \mathrm{~nm}$ dense spherical entities (likely the AuNCs). Some carboxylates present on the protein surface of AuNC-RNase-A were further condensed to vitamin B12 (vitB 12 ) using an EDC/NHS coupling strategy. The $\mathrm{VitB}_{12}-\mathrm{RNase}-\mathrm{A}-\mathrm{AuNCs}$ was then used for simultaneous targeting and imaging of cancerous cells (Caco-2) that internalized and transcitosed this nanoprobe by the intrinsic $\mathrm{VitB}_{12}$ uptake system. The specificity of $\mathrm{VitB}_{12}$-RNase-A-AuNCs consists in the potential of performing targeted oral delivery due to the presence of $\mathrm{VitB}_{12}$ that follows uptake pathaways via digestive system. Thus, a different type of nanoprobe delivery (oral delivery) that is more confortable could be coupled with in vivo imaging applications.

Fluorescent cytochrome $c$-AuNCs (cyt $c$-AuNCs) were prepared and used for delivery of cyt $c$ to cytoplasm and mitochondria as well as for imaging of live lung and brest cells [132]. Cyt $c$ is a membrane impermeable protein that is difficult to deliver to cytoplasm where plays a crucial role in cell apoptosis. The experiments showed that cyt $c$-AuNCs once entered the cell start to exchange with GSH present in cytoplasm displacing and releasing cyt $c$. For an accurate monitoring of cyt $c$ delivery inside cells, an organic fluorophore (Alexa Fluor 594) was covalently linked to the already prepared fluorescent cyt $c$-AuNCs. The experiments showed that cyt $c$-AuNCs were able to deliver cyt $c$ within approx. $60 \mathrm{~min}$ in four different cells lines and image mitochondria by FRET.

Blue-fluorescence emitting Lyz-AuNCs were loaded with DOX and employed for optical imaging of live cancer and non-cancer cells as well as for drug delivery [133]. Uptake of DOX-Lys-AuNCs was 15 to 20 times higher in A549 and MCF7 cancer cell lines than the uptake in non-cancer lung fibroblast WI38 and breast epithelial MCF10A cell lines. This enhanced uptake was accompanied by an increased cell death, indicating that lysozyme can be used as a vehicle for targeting cancer cell lines.

Li et al. synthesized FA-BSA-AuNCs for selective targeting FA receptors overexpressed on the surface of some tumor cells [134]. Condensation of FA onto BSA-AuNCs 
produced a non-fluorescent FA-BSA-AuNCs likely because the FA was close enough to BSA-AuNCs to promote fluorescence quenching. However, the fluorescence was recovered upon binding of FA to its receptors displayed on the cell surface, indicating that FA-BSAAuNCs can be used as a turn-on probe for monitoring the presence of FA receptors expressing cells. Two complementary techniques (dark field and fluorescence imaging) were used to determinate the targeting ability and intracellular uptake of FA-BSA-AuNCs into the MGC803 gastric cancer cell line [135]. The dark-field scattering displayed images with cells having an intense homogeneous cytoplasmic golden color due to the presence of BSAAuNCs. When analyzed by fluorescence $\left(\lambda_{\mathrm{em}}=588 \mathrm{~nm}\right)$, an intense cytoplasmic red color around the nucleus was observed, indicating the accumulation of FA-BSA-AuNCs in the cytoplasm. Thus, the two imaging techniques showed complementary and confirmed the results. In a different study, BSA-AuNCs were used for the encapsulation and delivery of a hydrophilic anticancerous drug (DOX) [136]. Quantitative analysis using two-photon fluorescent microscopy showed that the fluorescent species were, mostly found into the cell nuclei revealing weaker (in the cytoplasm) and brighter red luminescence (mainly in nucleus) for the HeLa cells incubated with DOX-BSA-AuNCs.

\subsubsection{Biomedical prospects}

\section{In vivo delivery and fluorescence imaging}

Wu et al. used BSA-AuNCs $\left(\lambda_{\mathrm{em}}=640 \mathrm{~nm}\right)$ for fluorescence detection of tumors in vivo [137]. The BSA-AuNCs were intravenously injected (tail vein) into nude Balb/c mice to vizualize the fluorescence in the superficial vasculature of the whole body. This fluorescence persisted for several hours (up to $5 \mathrm{~h}$ ) and decreased after $24 \mathrm{~h}$ except in the liver and bladder. No sign of toxicity was recorded over the 4 weeks period of treatment in mice. In the same study, mice bearing 2 types of tumors (MDA-MB-45 or HeLa) were intravenously injected with BSA-AuNCs (Figure 9). The fluorescence accumulated over time in the tumor (ratio fluorescence tumor/muscle $=15$ ), principally due to the small size of the BSA-AuNCs that can avoid RES and target the tumor through enhanced permeability and retention effect (EPR). Zhang et al. performed in vitro experiments with the BSA-AuNCs on two types of cancer cells (MCF-7, HeLa) and one normal cell line (L102) [138]. After $2 \mathrm{~h}$ of incubation with BSA-AuNCs, MCF-7 and HeLa displayed a large number of red emitting BSA-AuNCs specifically attached to the cell membrane and the intensity of fluorescence as the time of exposure increased. In contrast, L102 did not display any staining of the cell membrane or cellular uptake for the same incubation time and concentrations of BSA-AuNCs. Further in 
vivo experiments were performed in mice bearing MCF-7 or Hela tumors. The intratumoral delivery showed fluorescence 60 min after injection and was almost cleared out $24 \mathrm{~h}$ later.

$\mathrm{Hu}$ et al. developed FA-BSA-AuNCs $\left(\lambda_{\mathrm{em}}=655 \mathrm{~nm}\right)$ for active-targeting abilities and bioimaging applications [139]. In cancer tissues, this type of nanoprobe can strongly stain cancer cells due to FA that will target its receptors overexpressed on the surface of certain type of cancer cells. The FA-BSA-AuNCs confirmed its feasibility for faster $(1 \mathrm{~h} v \mathrm{~s} .4 \mathrm{~h})$ tumor detection/diagnosis by simultaneous microscopic imaging with bright field and fluorescent images in the same section since the two images are reciprocally complementary. In a different study FA-BSA-AuNCs has been covalently conjugated to an anticancerous drug cis-platin (Pt) yielding the Pt-FA-BSA-AuNCs [140]. The nanoprobe was tested on a highly aggressive $4 \mathrm{~T} 1$ breast cancer cell line and its orthotropic tumor model. It was observed that the Pt-FA-BSA-AuNCs could selectively accumulate inside the tumor and cancer cells. The in vitro results showed a significant cellular apoptosis upon intracellular activation of the cisplatin prodrug. The in vivo studies displayed high efficacy to simultaneously inhibit the growth and lung metastasis of 4T1 breast cancer [140].

BSA-AuNCs were also utilized by $\mathrm{Su}$ et al. to design a nanogel for targeted drug delivery at tumor site [141]. A thermo and $\mathrm{pH}$-responsive poly $(\mathrm{N}$-isopropyl acrylamide-coacrylic acid) nanogel was synthesized and then DOX/was encapsulated into the negatively charged swollen networks by electrostatic adsorption at $\mathrm{pH}$ 7.4. The as-prepared BSA-AuNCs $(2 \mathrm{~nm})$ were conjugated onto the surface of the nanogel, then a tumor targeting peptide (iRGD) was covalently attached on the surface of BSA. The in vitro experiments confirmed that the surface modification with iRGD/enhanced the intracellular uptake of DOX-iRGDBSA-AuNCs nanogel in the vein endothelial cells (HUVECs) and the extravascular tumor (B16). The DOX-iRGD-BSA-AuNCs nanogel could be detected and tracked in vivo using the fluorescence of BSA-AuNCs and the release of DOX in tumor could be controlled by the $\mathrm{pH}$ responsive properties of the nanogel. Following a similar strategy, a core-shell AuNCs nanocarrier was employed to deliver a hydrophobic anticancerous drug (camphotecin) (Table 1) $[142]$.

\section{NIRF/CT dual-modal bioimaging}

The FA-Lys-AuNCs with strong NIR fluorescence (QY of 19.61\%) could avoid biological interference and proved to be an efficient contrasting agent for NIRF/CT dualmodal bioimaging [143]. The in vitro studies were performed on HeLa cells (FR positive cell line) and revealed NIR fluorescence of FA-Lys-AuNCs in the cytoplasm after $4 \mathrm{~h}$ of 
incubation. The whole-body time depended imaging was studied by performing in vivo fluorescence of Lys-AuNCs on nude mice. The results confirmed that this nanoprobe is suitable for in vivo optical imaging. The FA-Lys-AuNCs was tested on tumor-bearing mouse demonstrating the ability of FA to target its receptor. The in vivo CT of a Kumming mouse before and after being administered with Lys-AuNCs showed positive signal enhancement in the liver and kidney due to the accumulation of the nanoprobe in these organs.

BSA-AuNCs with NIR fluorescence $\left(\lambda_{\mathrm{em}}=645 \mathrm{~nm}\right)$ and robust X-ray attenuation have been reported by Wang et al. [144]. To study the in vivo localization of BSA-AuNCs, the saline (control) and BSA-AuNCs (experimental) injected mice at $2 \mathrm{~h}$ post injection were sacrificed to generate ex vivo NIR images of the main organs. Only the organs containing BSA-AuNCs showed strong fluorescence (liver and kidneys) and weaker fluorescence (lungs and spleen). Further CT imaging has been accomplished by a comparison experiment between BSA-AuNCs and a commercial iodine based contrast agent (iopromide). As shown in Figure 10a the HU values increase with the concentration of the contrast materials, with lower concentrations of BSA-AuNCs matching the $\mathrm{HU}$ values of much higher concentrations of iopromide. The CT imaging showed visualization of the major organs (Figure 10c). Moreover, the BSA-AuNCs are excreted in the urine, resulting in clear visualization of the calyces, pelvis, ureters and bladder (Figure 10d). Thus label free BSA-AuNCs may be suitable for diagnosis of renal abnormalities on CT.

Insulin-AuNCs with red fluorescence $\left(\lambda_{\mathrm{em}}=670 \mathrm{~nm}\right)$ were reported by Chou et al. [122]. The confocal microscopy using fluorescence staining showed that insulin-AuNCs were internalized by $\mathrm{C} 2 \mathrm{C} 12$ (mouse myoblast) without specific distribution in the cytoplasm. Interesting was to discover that insulin-AuNCs posses a strong X-ray CT signal displayed at a concentration of $30 \mathrm{mg} / \mathrm{ml}$ as well as when entrapped within $\mathrm{C} 2 \mathrm{C} 12$ cells. These observations show that insulin-AuNCs could be used as a bimodal nanoprobe that can function as fluorescent and/or a contrasting agent for X-ray tomography. Additional insights on insulinAuNCs fluorescence properties were reported by Leblanc et al. [145].

\section{Radiotherapy}

Recently, Ghahremani et al. reported encouraging results with AS1411-BSA-AuNCs used as radiosensitizer for megavoltage radiation therapy of 4T1 breast cancer cells [146]. AS1411 is an aptamer that binds to nucleolin, a protein highly overexpressed in breast cancer cells. The AS1411 targets the nucleolin via AS1411 aptamer and the internalization follows shuttling mechanism from cell membrane to the nucleus. The experimental results showed 
indeed a high uptake and accumulation of AS1411-BSA-AuNCs in cancer cells. Further experiments performed with AS1411-BSA-AuNCs demonstrated its radiosensing efficacy even when low doses of radiations were used.

\section{In vivo toxicity and clearance}

A significant study was performed to compare in vivo renal clearance, and biodistribution of the $\mathrm{GSH}-\mathrm{Au}_{25} \mathrm{NCs}$ and $\mathrm{BSA}-\mathrm{Au}_{25} \mathrm{NCs}$ adduct [147]. The blood plasma experiments showed that GSH-AuNCs were more stable than BSA-AuNCs. The biodistribution showed that $\mathrm{BSA}-\mathrm{Au}_{25} \mathrm{NCs}$ mainly accumulated in the liver and spleen and the $\mathrm{GSH}-\mathrm{Au}_{25} \mathrm{NCs}$ had low concentration in all organs. It was observed that $36 \%$ of GSH$\mathrm{Au}_{25} \mathrm{NCs}$ were cleared out of the body after $24 \mathrm{~h}$ but only $1 \%$ of $\mathrm{BSA}-\mathrm{Au}_{25} \mathrm{NCs}$ were cleared in the same interval of time. Additionally, $94 \%$ and $5 \%$ of GSH-Au ${ }_{25} \mathrm{NCs}$ and $\mathrm{BSA}-\mathrm{Au}_{25} \mathrm{NCs}$ were metabolized after 28 days, respectively. The study demonstrated that the BSA- $\mathrm{Au}_{25} \mathrm{NCs}$ adduct accumulate in liver and spleen whereas the GSH-Au ${ }_{25} \mathrm{NCs}$ were almost cleared by kidney and have induced no toxicity responses.

\section{Conclusion and outlook}

The advantages achieved while using AuNCs/lean on their specific and intrinsic physicochemical properties. This review points out the possibility to choose a specific type of AuNCs according to aim of application such as use of non-fluorescent AuNCs when interested only in EM imaging and custom of fluorescent AuNCs while going for applications that demand an adequate traceability inside live cells or organism. Size, structure and surface functionalities define the overall properties of AuNCs as a nanodelivery system and dictate its intracellular fate. The special benefit of AuNCs is the ultra-small size regime $(\leq 2 \mathrm{~nm})$ that allows efficient cellular uptake and delivery. Additionally, surface functionalities contribute to the stability, interaction and transport of AuNCs outside and inside cells.

One of the most important features of the AuNCs is the opportunity of using their specific properties along with other innovative approaches for imaging and/or therapeutic applications. AuNCs protected with small ligands such as phosphines or thiolates have displayed utility especially in imaging. In addition, these AuNCs represent a versatile platform for delivery of diverse therapeutic molecules due to the facility to link molecules to their metallic structure. Moreover, the great advantage while working with AuNCs and not with AuNPs is that they are small enough to be removed from the body via glomerular filtration. This ability offers the opportunity to employ different ligand protected-AuNCs for 
biomedical applications. Although peptides-AuNCs and proteins-AuNCs have already shown the first prospective results in imaging and/or therapy, many parameters need to be clarified in order to better control these promising nanosystems. First of all, a good understanding of their structure would bring information at the atomic level and thus their applications could be better oriented. Secondly, an improved characterization by complementary techniques would be helpful in understanding the structure-activity relationships, which is still poorly described at fundamental level.

In this entire context, one of the main requirements remains a challenge for further development and improvement: the way of exploiting the properties of AuNCs as nanoprobes with minimum side effects. Difficulties are still to be overcome concerning the administration routes and specific targeting. Detailed studies concerning the interactions mechanisms while delivery in vitro or in vivo would better clarify these missing points. Further research should focus on these aspects in order to entirely benefit of the considerable potential of AuNCs when interested to endeavor for biomedical applications.

\section{Conflicts of interest}

The authors declare no conflicts of interest. 


\section{Bibliography}

[1] Dreaden EC, Alkilany AM, Huang XH, Murphy CJ, El-Sayed MA., Dreaden EC, Alkilany AM, Huang XH, Murphy CJ, El-Sayed MA. The golden age: gold nanoparticles for biomedicine. Chemical Society Reviews. 2012;41:2740-79., (n.d.).

[2] X. Yang, M. Yang, B. Pang, M. Vara, Y. Xia, Gold Nanomaterials at Work in Biomedicine, Chem. Rev. 115 (2015) 10410-10488. doi:10.1021/acs.chemrev.5b00193.

[3] L. Dykman, N. Khlebtsov, Gold nanoparticles in biomedical applications: recent advances and perspectives, Chem. Soc. Rev. 41 (2012) 2256-2282. doi:10.1039/C1CS15166E.

[4] D.A. Giljohann, D.S. Seferos, W.L. Daniel, M.D. Massich, P.C. Patel, C.A. Mirkin, Gold Nanoparticles for Biology and Medicine, Angew. Chem. Int. Ed. 49 (2010) 3280-3294. doi:10.1002/anie.200904359.

[5] C. Kumara, X. Zuo, D.A. Cullen, A. Dass, Faradaurate-940: Synthesis, Mass Spectrometry, Electron Microscopy, High-Energy X-ray Diffraction, and X-ray Scattering Study of $\mathrm{Au} \sim 940 \pm 20$ (SR) $\sim 160 \pm 4$ Nanocrystals, ACS Nano. 8 (2014) 6431-6439. doi:10.1021/nn501970v.

[6] R. Jin, Atomically precise metal nanoclusters: stable sizes and optical properties, Nanoscale. 7 (2015) 1549-1565. doi:10.1039/C4NR05794E.

[7] R. Jin, Quantum sized, thiolate-protected gold nanoclusters, Nanoscale. 2 (2010) 343362. doi:10.1039/B9NR00160C.

[8] M. Azubel, J. Koivisto, S. Malola, D. Bushnell, G.L. Hura, A.L. Koh, H. Tsunoyama, T. Tsukuda, M. Pettersson, H. Hakkinen, R.D. Kornberg, Electron microscopy of gold nanoparticles at atomic resolution, Science. 345 (2014) 909-912. doi:10.1126/science.1251959.

[9] S.H. Yau, O. Varnavski, T. Goodson, An Ultrafast Look at Au Nanoclusters, Acc. Chem. Res. 46 (2013) 1506-1516. doi:10.1021/ar300280w.

[10] K.Z. Milowska, J.K. Stolarczyk, Role of ligand-ligand vs. core-core interactions in gold nanoclusters, Phys Chem Chem Phys. 18 (2016) 12716-12724. doi:10.1039/C5CP06795B.

[11] A. Fernando, K.L.D.M. Weerawardene, N.V. Karimova, C.M. Aikens, Quantum Mechanical Studies of Large Metal, Metal Oxide, and Metal Chalcogenide Nanoparticles and Clusters, Chem. Rev. 115 (2015) 6112-6216. doi:10.1021/cr500506r.

[12] B. Duncan, C. Kim, V.M. Rotello, Gold nanoparticle platforms as drug and biomacromolecule delivery systems, J. Controlled Release. 148 (2010) 122-127. doi:10.1016/j.jconrel.2010.06.004.

[13] Z. Luo, X. Yuan, Y. Yu, Q. Zhang, D.T. Leong, J.Y. Lee, J. Xie, From AggregationInduced Emission of $\mathrm{Au}(\mathrm{I})$-Thiolate Complexes to Ultrabright $\mathrm{Au}(0) @ \mathrm{Au}(\mathrm{I})$-Thiolate CoreShell Nanoclusters, J. Am. Chem. Soc. 134 (2012) 16662-16670. doi:10.1021/ja306199p.

[14] S.D. Perrault, C. Walkey, T. Jennings, H.C. Fischer, W.C.W. Chan, Mediating Tumor Targeting Efficiency of Nanoparticles Through Design, Nano Lett. 9 (2009) 1909-1915. doi:10.1021/n1900031y.

[15] O.A. Wong, R.J. Hansen, T.W. Ni, C.L. Heinecke, W.S. Compel, D.L. Gustafson, C.J. Ackerson, Structure-activity relationships for biodistribution, pharmacokinetics, and excretion of atomically precise nanoclusters in a murine model, Nanoscale. 5 (2013) 10525. doi: $10.1039 / \mathrm{c} 3 \mathrm{nr} 03121 \mathrm{~g}$.

[16] F. Charbgoo, M. Nejabat, K. Abnous, F. Soltani, S.M. Taghdisi, M. Alibolandi, W. Thomas Shier, T.W.J. Steele, M. Ramezani, Gold nanoparticle should understand protein corona for being a clinical nanomaterial, J. Controlled Release. 272 (2018) 39-53. doi:10.1016/j.jconrel.2018.01.002. 
[17] A.S. Thakor, J. Jokerst, C. Zavaleta, T.F. Massoud, S.S. Gambhir, Gold Nanoparticles: A Revival in Precious Metal Administration to Patients, Nano Lett. 11 (2011) 4029-4036. doi:10.1021/n1202559p.

[18] H. Soo Choi, W. Liu, P. Misra, E. Tanaka, J.P. Zimmer, B. Itty Ipe, M.G. Bawendi, J.V. Frangioni, Renal clearance of quantum dots, Nat. Biotechnol. 25 (2007) 1165-1170. doi:10.1038/nbt1340.

[19] L.-Y. Chen, C.-W. Wang, Z. Yuan, H.-T. Chang, Fluorescent Gold Nanoclusters: Recent Advances in Sensing and Imaging, Anal. Chem. 87 (2015) 216-229. doi:10.1021/ac503636j.

[20] M. Cui, Y. Zhao, Q. Song, Synthesis, optical properties and applications of ultra-small luminescent gold nanoclusters, TrAC Trends Anal. Chem. 57 (2014) 73-82. doi:10.1016/j.trac.2014.02.005.

[21] L. Shang, S. Dong, G.U. Nienhaus, Ultra-small fluorescent metal nanoclusters: Synthesis and biological applications, Nano Today. 6 (2011) 401-418. doi:10.1016/j.nantod.2011.06.004.

[22] Z. Luo, K. Zheng, J. Xie, Engineering ultrasmall water-soluble gold and silver nanoclusters for biomedical applications, Chem Commun. 50 (2014) 5143-5155. doi:10.1039/C3CC47512C.

[23] M. McPartlin, R. Mason, L. Malatesta, Novel cluster complexes of gold (0)-gold (I), J. Chem. Soc. Chem. Commun. (1969) 334-334.

[24] D. Safer, J. Hainfeld, J. Wall, J. Reardon, Biospecific/labeling with undecagold: visualization of the biotin-binding site on avidin, Science. 218 (1982) 290. doi:10.1126/science.7123234.

[25] J.E. Reardon, P.A. Frey, Synthesis of undecagold cluster molecules as biochemical labeling reagents. 1. Monoacyl- and mono[N-(succinimidooxy)succinyl]undecagold clusters, Biochemistry. 23 (1984) 3849-3856. doi:10.1021/bi00312a009.

[26] D. Safer, L. Bolinger, J.S. Leigh Jr., Undecagold clusters for site-specific labeling of biological macromolecules: simplified preparation and model applications, J. Inorg. Biochem. 26 (1986) 77-91. doi:10.1016/0162-0134(86)80001-0.

[27] J.F. Hainfeld, Gold cluster-labelled antibodies, Nature. 333 (1988) 281-282. doi:10.1038/333281a0.

[28] J.F. Hainfeld, F.R. Furuya, Derivatized gold clusters and antibody-gold cluster conjugates, (1994). https://www.google.com/patents/US5360895.

[29] R.D. Powell, J.F. Hainfeld, Preparation and high-resolution microscopy of gold cluster labeled nucleic acid conjugates and nanodevices, Micron. 42 (2011) 163-174. doi:10.1016/j.micron.2010.08.007.

[30] T. Takizawa, J.M. Robinson, Use of 1.4-nm immunogold particles for immunocytochemistry on ultra-thin cryosections., J. Histochem. Cytochem. 42 (1994) 16151623.

[31] R.W. Burry, D.D. Vandré, D.M. Hayes, Silver enhancement of gold antibody probes in pre-embedding electron microscopic immunocytochemistry., J. Histochem. Cytochem. 40 (1992) 1849-1856. doi:10.1177/40.12.1453003.

[32] T. Takizawa, R.D. Powell, J.F. Hainfeld, J.M. Robinson, FluoroNanogold: an important probe for correlative microscopy, J. Chem. Biol. 8 (2015) 129-142. doi:10.1007/s12154-015-0145-1.

[33] K. Cortese, A. Diaspro, C. Tacchetti, Advanced Correlative Light/Electron Microscopy: Current Methods and New Developments Using Tokuyasu Cryosections, J. Histochem. Cytochem. 57 (2009) 1103-1112. doi:10.1369/jhc.2009.954214.

[34] R.D. Powell, C.M. Halsey, D.L. Spector, S.L. Kaurin, J. McCann, J.F. Hainfeld, A covalent fluorescent-gold immunoprobe: simultaneous detection of a pre-mRNA splicing 
factor by light and electron microscopy, J. Histochem. Cytochem. 45 (1997) 947-956.

[35] R.D. Powell, C.M. Halsey, J.F. Hainfeld, Combined fluorescent and gold immunoprobes: reagents and methods for correlative light and electron microscopy, Microsc. Res. Tech. 42 (1998) 2-12.

[36] T. Takizawa, K. Suzuki, J.M. Robinson, Correlative microscopy using FluoroNanogold on ultrathin cryosections: proof of principle, J. Histochem. Cytochem. 46 (1998) 1097-1102.

[37] T. Takizawa, J.M. Robinson, FluoroNanogold is a bifunctional immunoprobe for correlative fluorescence and electron microscopy, J. Histochem. Cytochem. 48 (2000) $481-$ 485.

[38] J.M. Robinson, T. Takizawa, D.D. Vandré, Enhanced labeling efficiency using ultrasmall immunogold probes: immunocytochemistry, J. Histochem. Cytochem. 48 (2000) 487-492.

[39] J.F. Hainfeld, D.N. Slatkin, H.M. Smilowitz, The use of gold nanoparticles to enhance radiotherapy in mice, Phys. Med. Biol. 49 (2004) N309-N315. doi:10.1088/00319155/49/18/N03.

[40] J.F. Hainfeld, F.A. Dilmanian, D.N. Slatkin, H.M. Smilowitz, Radiotherapy enhancement with gold nanoparticles, J. Pharm. Pharmacol. 60 (2008) 977-985. doi:10.1211/jpp.60.8.0005.

[41] J.F. Hainfeld, F.A. Dilmanian, Z. Zhong, D.N. Slatkin, J.A. Kalef-Ezra, H.M. Smilowitz, Gold nanoparticles enhance the radiation therapy of a murine squamous cell carcinoma, Phys. Med. Biol. 55 (2010) 3045-3059. doi:10.1088/0031-9155/55/11/004.

[42] J.F. Hainfeld, H.M. Smilowitz, M.J. O’Connor, F.A. Dilmanian, D.N. Slatkin, Gold nanoparticle imaging and radiotherapy of brain tumors in mice, Nanomed. 8 (2013) 16011609. doi:10.2217/nnm.12.165.

[43] H. Häkkinen, The gold-sulfur interface at the nanoscale, Nat. Chem. 4 (2012) $443-$ 455. doi:10.1038/nchem.1352.

[44] D. Stellwagen, A. Weber, G.L. Bovenkamp, R. Jin, J.H. Bitter, C.S.S.R. Kumar, Ligand control in thiol stabilized Au38 clusters, RSC Adv. 2 (2012) 2276. doi:10.1039/c2ra00747a.

[45] M. Brust, J. Fink, D. Bethell, D.J. Schiffrin, C. Kiely, Synthesis and reactions of functionalised gold nanoparticles, J. Chem. Soc. Chem. Commun. (1995) 1655. doi:10.1039/c39950001655.

[46] C.J. Ackerson, P.D. Jadzinsky, R.D. Kornberg, Thiolate Ligands for Synthesis of Water-Soluble Gold Clusters, J. Am. Chem. Soc. 127 (2005) 6550-6551. doi:10.1021/ja046114i.

[47] C.J. Ackerson, P.D. Jadzinsky, J.Z. Sexton, D.A. Bushnell, R.D. Kornberg, Synthesis and Bioconjugation of 2 and $3 \mathrm{~nm}$-Diameter Gold Nanoparticles, Bioconjug. Chem. 21 (2010) 214-218. doi:10.1021/bc900135d.

[48] L.M. Tvedte, C.J. Ackerson, Size-Focusing Synthesis of Gold Nanoclusters with $p$ Mercaptobenzoic Acid, J.Phys. Chem. A. 118 (2014) 8124-8128. doi:10.1021/jp5001946.

[49] O.A. Wong, W.S. Compel, C.J. Ackerson, Combinatorial Discovery of Cosolvent Systems for Production of Narrow Dispersion Thiolate-Protected Gold Nanoparticles, ACS Comb. Sci. 17 (2015) 11-18. doi:10.1021/co500072c.

[50] K. Salorinne, S. Malola, O.A. Wong, C.D. Rithner, X. Chen, C.J. Ackerson, H. Häkkinen, Conformation and dynamics of the ligand shell of a water-soluble Au102 nanoparticle, Nat. Commun. 7 (2016) 10401. doi:10.1038/ncomms 10401.

[51] S.R. Johnson, S.D. Evans, R. Brydson, Influence of a Terminal Functionality on the Physical Properties of Surfactant-Stabilized Gold Nanoparticles, Langmuir. 14 (1998) 66396647. doi:10.1021/la9711342. 
[52] C.L. Heinecke, T.W. Ni, S. Malola, V. Mäkinen, O.A. Wong, H. Häkkinen, C.J. Ackerson, Structural and Theoretical Basis for Ligand Exchange on Thiolate Monolayer Protected Gold Nanoclusters, J. Am. Chem. Soc. 134 (2012) 13316-13322. doi:10.1021/ja3032339.

[53] O.A. Wong, C.L. Heinecke, A.R. Simone, R.L. Whetten, C.J. Ackerson, Ligand symmetry-equivalence on thiolate protected gold nanoclusters determined by NMR spectroscopy, Nanoscale. 4 (2012) 4099. doi:10.1039/c2nr30259d.

[54] Z. Huang, Y. Ishida, K. Narita, T. Yonezawa, Kinetics of Cationic-Ligand-Exchange Reactions in $\mathrm{Au}{ }_{25}$ Nanoclusters, J. Phys. Chem. C. 122 (2018) 18142-18150. doi:10.1021/acs.jpcc.8b05371.

[55] V. Marjomaki, T. Lahtinen, M. Martikainen, J. Koivisto, S. Malola, K. Salorinne, M. Pettersson, H. Hakkinen, Site-specific targeting of enterovirus capsid by functionalized monodisperse gold nanoclusters, Proc. Natl. Acad. Sci. 111 (2014) 1277-1281. doi:10.1073/pnas.1310973111.

[56] M. Martikainen, K. Salorinne, T. Lahtinen, S. Malola, P. Permi, H. Häkkinen, V. Marjomäki, Hydrophobic pocket targeting probes for enteroviruses, Nanoscale. 7 (2015) 17457-17467. doi:10.1039/C5NR04139B.

[57] V. Postupalenko, D. Desplancq, I. Orlov, Y. Arntz, D. Spehner, Y. Mely, B.P. Klaholz, P. Schultz, E. Weiss, G. Zuber, Protein Delivery System Containing a NickelImmobilized Polymer for Multimerization of Affinity-Purified His-Tagged Proteins Enhances Cytosolic Transfer, Angew. Chem. Int. Ed. 54 (2015) 10583-10586. doi:10.1002/anie.201505437.

[58] D. Desplancq, N. Groysbeck, M. Chiper, E. Weiss, B. Frisch, J.-M. Strub, S. Cianferani, S. Zafeiratos, E. Moeglin, X. Holy, A.L. Favier, S. De Carlo, P. Schultz, D. Spehner, G. Zuber, Cytosolic Diffusion and Peptide-Assisted Nuclear Shuttling of PeptideSubstituted Circa 102 Gold Atom Nanoclusters in Living Cells, ACS Appl. Nano Mater. 1 (2018) 4236-4246. doi:10.1021/acsanm.8b00988.

[59] M.-C. Bowman, T.E. Ballard, C.J. Ackerson, D.L. Feldheim, D.M. Margolis, C. Melander, Inhibition of HIV Fusion with Multivalent Gold Nanoparticles, J. Am. Chem. Soc. 130 (2008) 6896-6897. doi:10.1021/ja710321g.

[60] R. Mout, M. Ray, G. Yesilbag Tonga, Y.-W. Lee, T. Tay, K. Sasaki, V.M. Rotello, Direct cytosolic delivery of CRISPR/Cas9-ribonucleoprotein for efficient gene editing., ACS Nano. 11 (2017) 2452-2458. doi:10.1021/acsnano.6b07600.

[61] M. Ray, Y.-W. Lee, J. Hardie, R. Mout, G. Yeşilbag Tonga, M.E. Farkas, V.M. Rotello, CRISPRed Macrophages for Cell-Based Cancer Immunotherapy, Bioconjug. Chem. 29 (2018) 445-450. doi:10.1021/acs.bioconjchem.7b00768.

[62] X.-D. Zhang, Z. Luo, J. Chen, X. Shen, S. Song, Y. Sun, S. Fan, F. Fan, D.T. Leong, J. Xie, Ultrasmall $\mathrm{Au}{ }_{10-12}$ (SG) 10-12 Nanomolecules for High Tumor Specificity and Cancer Radiotherapy, Adv. Mater. 26 (2014) 4565-4568. doi:10.1002/adma.201400866.

[63] C.A. Simpson, K.J. Salleng, D.E. Cliffel, D.L. Feldheim, In vivo toxicity, biodistribution, and clearance of glutathione-coated gold nanoparticles, Nanomedicine Nanotechnol. Biol. Med. 9 (2013) 257-263. doi:10.1016/j.nano.2012.06.002.

[64] Y. Jiang, S. Huo, T. Mizuhara, R. Das, Y.-W. Lee, S. Hou, D.F. Moyano, B. Duncan, X.-J. Liang, V.M. Rotello, The Interplay of Size and Surface Functionality on the Cellular Uptake of Sub-10 nm Gold Nanoparticles, ACS Nano. 9 (2015) 9986-9993. doi:10.1021/acsnano.5b03521.

[65] S.G. Elci, Y. Jiang, B. Yan, S.T. Kim, K. Saha, D.F. Moyano, G. Yesilbag Tonga, L.C. Jackson, V.M. Rotello, R.W. Vachet, Surface Charge Controls the Suborgan Biodistributions of Gold Nanoparticles, ACS Nano. 10 (2016) 5536-5542. doi:10.1021/acsnano.6b02086. 
[66] A.S. Goldsborough, M.D. Handley, A.E. Dulcey, K.M. Pluchino, P. Kannan, K.R. Brimacombe, M.D. Hall, G. Griffiths, M.M. Gottesman, Collateral Sensitivity of MultidrugResistant Cells to the Orphan Drug Tiopronin, J. Med. Chem. 54 (2011) 4987-4997. doi:10.1021/jm2001663.

[67] K. Huang, H. Ma, J. Liu, S. Huo, A. Kumar, T. Wei, X. Zhang, S. Jin, Y. Gan, P.C. Wang, S. He, X. Zhang, X.-J. Liang, Size-Dependent Localization and Penetration of Ultrasmall Gold Nanoparticles in Cancer Cells, Multicellular Spheroids, and Tumors in Vivo, ACS Nano. 6 (2012) 4483-4493. doi:10.1021/nn301282m.

[68] A.C. Templeton, S. Chen, S.M. Gross, R.W. Murray, Water-Soluble, Isolable Gold Clusters Protected by Tiopronin and Coenzyme A Monolayers, Langmuir. 15 (1999) 66-76. doi:10.1021/la9808420.

[69] C.A. Simpson, B.J. Huffman, A.E. Gerdon, D.E. Cliffel, Unexpected Toxicity of Monolayer Protected Gold Clusters Eliminated by PEG-Thiol Place Exchange Reactions, Chem. Res. Toxicol. 23 (2010) 1608-1616. doi:10.1021/tx100209t.

[70] C.A. Simpson, A.C. Agrawal, A. Balinski, K.M. Harkness, D.E. Cliffel, Short-Chain PEG Mixed Monolayer Protected Gold Clusters Increase Clearance and Red Blood Cell Counts, ACS Nano. 5 (2011) 3577-3584. doi:10.1021/nn103148x.

[71] A. Cantelli, G. Guidetti, J. Manzi, V. Caponetti, M. Montalti, Towards Ultra-Bright Gold Nanoclusters: Towards Ultra-Bright Gold Nanoclusters, Eur. J. Inorg. Chem. 2017 (2017) 5068-5084. doi:10.1002/ejic.201700735.

[72] E. Oh, K. Susumu, R. Goswami, H. Mattoussi, One-Phase Synthesis of Water-Soluble Gold Nanoparticles with Control over Size and Surface Functionalities, Langmuir. 26 (2010) 7604-7613. doi:10.1021/la904438s.

[73] F. Aldeek, M.A.H. Muhammed, G. Palui, N. Zhan, H. Mattoussi, Growth of Highly Fluorescent Polyethylene Glycol- and Zwitterion-Functionalized Gold Nanoclusters, ACS Nano. 7 (2013) 2509-2521. doi:10.1021/nn305856t.

[74] D. Mishra, F. Aldeek, E. Lochner, G. Palui, B. Zeng, S. Mackowski, H. Mattoussi, Aqueous Growth of Gold Clusters with Tunable Fluorescence Using Photochemically Modified Lipoic Acid-Based Ligands, Langmuir. 32 (2016) 6445-6458. doi:10.1021/acs.langmuir.6b00950.

[75] J. Sun, J. Zhang, Y. Jin, 11-Mercaptoundecanoic acid directed one-pot synthesis of water-soluble fluorescent gold nanoclusters and their use as probes for sensitive and selective detection of $\mathrm{Cr}^{3+}$ and $\mathrm{Cr}^{6+}$, J Mater Chem C. 1 (2013) 138-143. doi:10.1039/C2TC00021K.

[76] S. Xu, T. Gao, X. Feng, Y. Mao, P. Liu, X. Yu, X. Luo, Dual ligand co-functionalized fluorescent gold nanoclusters for the "turn on" sensing of glutathione in tumor cells, J. Mater. Chem. B. 4 (2016) 1270-1275. doi:10.1039/C5TB02195B.

[77] X. Yuan, N. Goswami, W. Chen, Q. Yao, J. Xie, Insights into the effect of surface ligands on the optical properties of thiolated $\mathrm{Au}_{25}$ nanoclusters, Chem Commun. 52 (2016) 5234-5237. doi:10.1039/C6CC00857G.

[78] X. Liu, C, Li, J. Xu, J. Lv, M. Zhu, Y. Guo, S. Cui, H. Liu, S. Wang, Y. Li, Surfactant-Free Synthesis and Functionalization of Highly Fluorescent Gold Quantum Dots, J. Phys. Chem. C. 112 (2008) 10778-10783. doi:10.1021/jp8028227.

[79] X. Zhang, F.-G. Wu, P. Liu, H.-Y. Wang, N. Gu, Z. Chen, Synthesis of ultrastable and multifunctional gold nanoclusters with enhanced fluorescence and potential anticancer drug delivery application, J. Colloid Interface Sci. 455 (2015) 6-15. doi:10.1016/j.jcis.2015.05.029.

[80] B. Chatterjee, A. Ghoshal, A. Chattopadhyay, S.S. Ghosh, dGTP-Templated Luminescent Gold Nanocluster-Based Composite Nanoparticles for Cancer Theranostics, ACS Biomater. Sci. Eng. 4 (2018) 1005-1012. doi:10.1021/acsbiomaterials.7b00980.

[81] T.D. Fernández, J.R. Pearson, M.P. Leal, M.J. Torres, M. Blanca, C. Mayorga, X. Le 
Guével, Intracellular accumulation and immunological properties of fluorescent gold nanoclusters in human dendritic cells, Biomaterials. 43 (2015) 1-12. doi:10.1016/j.biomaterials.2014.11.045.

[82] T.G. Schaaff, G. Knight, M.N. Shafigullin, R.F. Borkman, R.L. Whetten, Isolation and Selected Properties of a 10.4 kDa Gold:Glutathione Cluster Compound, J. Phys. Chem. B. 102 (1998) 10643-10646. doi:10.1021/jp9830528.

[83] Y. Negishi, K. Nobusada, T. Tsukuda, Glutathione-Protected Gold Clusters Revisited: Bridging the Gap between Gold(I)-Thiolate Complexes and Thiolate-Protected Gold Nanocrystals, J. Am. Chem. Soc. 127 (2005) 5261-5270. doi:10.1021/ja042218h.

[84] Z. Wu, R. Jin, On the Ligand's Role in the Fluorescence of Gold Nanoclusters, Nano Lett. 10 (2010) 2568-2573. doi:10.1021/nl101225f.

[85] T. Huang, R.W. Murray, Visible Luminescence of Water-Soluble MonolayerProtected Gold Clusters, J. Phys. Chem. B. 105 (2001) 12498-12502. doi:10.1021/jp0041151.

[86] L. Polavarapu, M. Manna, Q.-H. Xu, Biocompatible glutathione capped gold clusters as one- and two-photon excitation fluorescence contrast agents for live cells imaging, Nanoscale. 3 (2011) 429-434. doi:10.1039/C0NR00458H.

[87] Y. Zhang, J. Li, H. Jiang, C. Zhao, X. Wang, Rapid tumor bioimaging and photothermal treatment based on GSH-capped red fluorescent gold nanoclusters, RSC Adv. 6 (2016) 63331-63337. doi:10.1039/C6RA10409F.

[88] C. Zhang, C. Li, Y. Liu, J. Zhang, C. Bao, S. Liang, Q. Wang, Y. Yang, H. Fu, K. Wang, D. Cui, Gold Nanoclusters-Based Nanoprobes for Simultaneous Fluorescence Imaging and Targeted Photodynamic Therapy with Superior Penetration and Retention Behavior in Tumors, Adv. Funct. Mater. 25 (2015) 1314-1325. doi:10.1002/adfm.201403095.

[89] G. Zuber, L. Zammut-Italiano, E. Dauty, J.-P. Behr, Targeted Gene Delivery to Cancer Cells: Directed Assembly of Nanometric DNA Particles Coated with Folic Acid, Angew. Chem. Int. Ed. 42 (2003) 2666-2669. doi:10.1002/anie.200250446.

[90] F. Xia, W. Hou, Y. Liu, W. Wang, Y. Han, M. Yang, X. Zhi, C. Li, D. Qi, T. Li, J. Martinez de la Fuente, C. Zhang, J. Song, D. Cui, Cytokine induced killer cells-assisted delivery of chlorin e6 mediated self-assembled gold nanoclusters to tumors for imaging and immuno-photodynamic therapy, Biomaterials. $170 \quad$ (2018) 1-11. doi:10.1016/j.biomaterials.2018.03.048.

[91] P. Wang, L. Zhang, Y. Xie, N. Wang, R. Tang, W. Zheng, X. Jiang, Genome Editing for Cancer Therapy: Delivery of Cas9 Protein/sgRNA Plasmid via a Gold Nanocluster/Lipid Core-Shell Nanocarrier, Adv. Sci. 4 (2017) 1700175. doi:10.1002/advs.201700175.

[92] M. Chiper, K. Niederreither, G. Zuber, Transduction Methods for Cytosolic Delivery of Proteins and Bioconjugates into Living Cells, Adv. Healthc. Mater. 7 (2018) 1701040. doi:10.1002/adhm.201701040.

[93] A. Yahia-Ammar, D. Sierra, F. Mérola, N. Hildebrandt, X. Le Guével, SelfAssembled Gold Nanoclusters for Bright Fluorescence Imaging and Enhanced Drug Delivery, ACS Nano. 10 (2016) 2591-2599. doi:10.1021/acsnano.5b07596.

[94] Y. Wang, Y. Cui, Y. Zhao, R. Liu, Z. Sun, W. Li, X. Gao, Bifunctional peptides that precisely biomineralize $\mathrm{Au}$ clusters and specifically stain cell nuclei, Chem Commun. 48 (2012) 871-873. doi:10.1039/C1CC15926G.

[95] R. Liu, Y. Wang, Q. Yuan, D. An, J. Li, X. Gao, The Au clusters induce tumor cell apoptosis via specifically targeting thioredoxin reductase 1 (TrxR1) and suppressing its activity, Chem. Commun. 50 (2014) 10687. doi:10.1039/C4CC03320E.

[96] R. de la Rica, L.W. Chow, C.-M. Horejs, M. Mazo, C. Chiappini, E.T. Pashuck, R. Bitton, M.M. Stevens, A designer peptide as a template for growing Au nanoclusters, Chem. Commun. 50 (2014) 10648. doi:10.1039/C4CC03240C.

[97] L. Shang, R.M. Dörlich, S. Brandholt, R. Schneider, V. Trouillet, M. Bruns, D. 
Gerthsen, G.U. Nienhaus, Facile preparation of water-soluble fluorescent gold nanoclusters for cellular imaging applications, Nanoscale. 3 (2011) 2009. doi:10.1039/c0nr00947d.

[98] X. Yang, L. Gan, L. Han, D. Li, J. Wang, E. Wang, Facile preparation of chiral penicillamine protected gold nanoclusters and their applications in cell imaging, Chem. Commun. 49 (2013) 2302. doi:10.1039/c3cc00200d.

[99] X. Yang, M. Shi, R. Zhou, X. Chen, H. Chen, Blending of HAuCl4 and histidine in aqueous solution: a simple approach to the Au10 cluster, Nanoscale. 3 (2011) 2596. doi:10.1039/c1nr10287g.

[100] X. Mu, L. Qi, P. Dong, J. Qiao, J. Hou, Z. Nie, H. Ma, Facile one-pot synthesis of 1proline-stabilized fluorescent gold nanoclusters and its application as sensing probes for serum iron, Biosens. Bioelectron. 49 (2013) 249-255. doi:10.1016/j.bios.2013.05.019.

[101] V. Venkatesh, A. Shukla, S. Sivakumar, S. Verma, Purine-Stabilized Green Fluorescent Gold Nanoclusters for Cell Nuclei Imaging Applications, ACS Appl. Mater. Interfaces. 6 (2014) 2185-2191. doi:10.1021/am405345h.

[102] Y. Bao, H.-C. Yeh, C. Zhong, S.A. Ivanov, J.K. Sharma, M.L. Neidig, D.M. Vu, A.P. Shreve, R.B. Dyer, J.H. Werner, J.S. Martinez, Formation and Stabilization of Fluorescent Gold Nanoclusters Using Small Molecules ${ }^{\dagger}$, J. Phys. Chem. C. 114 (2010) 15879-15882. doi:10.1021/jp909580z.

[103] H. Chen, B. Li, C. Wang, X. Zhang, Z. Cheng, X. Dai, R. Zhu, Y. Gu, Characterization of a fluorescence probe based on gold nanoclusters for cell and animal imaging, Nanotechnology. 24 (2013) 055704. doi:10.1088/0957-4484/24/5/055704.

[104] J. Guo, C. Du, L. Shan, H. Zhu, B. Xue, Z. Qian, S. Achilefu, Y. Gu, Comparison of near-infrared fluorescent deoxyglucose probes with different dyes for tumor diagnosis in vivo: COMPARISON OF DIFFERENT NIR DEOXYGLUCOSE PROBES, Contrast Media Mol. Imaging. 7 (2012) 289-301. doi:10.1002/cmmi.496.

[105] Y. Chen, X. Zheng, X. Wang, C. Wang, Y. Ding, X. Jiang, Near-Infrared Emitting Gold Cluster-Poly(acrylic acid) Hybrid Nanogels, ACS Macro Lett. 3 (2014) 74-76. doi:10.1021/mz4005748.

[106] N.L. Rosi, Oligonucleotide-Modified Gold Nanoparticles for Intracellular Gene Regulation, Science. 312 (2006) 1027-1030. doi:10.1126/science.1125559.

[107] Y. Chen, M.L. Phipps, J.H. Werner, S. Chakraborty, J.S. Martinez, DNA Templated Metal Nanoclusters: From Emergent Properties to Unique Applications, Acc. Chem. Res. 51 (2018) 2756-2763. doi:10.1021/acs.accounts.8b00366.

[108] A. Pandya, A.N. Lad, S.P. Singh, R. Shanker, DNA assembled metal nanoclusters: synthesis to novel applications, RSC Adv. 6 (2016) 113095-113114. doi:10.1039/C6RA24098D.

[109] W. Zhou, R. Saran, J. Liu, Metal Sensing by DNA, Chem. Rev. 117 (2017) 82728325. doi:10.1021/acs.chemrev.7b00063.

[110] R. Zhou, M. Shi, X. Chen, M. Wang, H. Chen, Atomically Monodispersed and Fluorescent Sub-Nanometer Gold Clusters Created by Biomolecule-Assisted Etching of Nanometer-Sized Gold Particles and Rods, Chem. - Eur. J. 15 (2009) 4944-4951. doi:10.1002/chem.200802743.

[111] T.A.C. Kennedy, J.L. MacLean, J. Liu, Blue emitting gold nanoclusters templated by poly-cytosine DNA at low $\mathrm{pH}$ and poly-adenine DNA at neutral $\mathrm{pH}$, Chem. Commun. 48 (2012) 6845. doi:10.1039/c2cc32841k.

[112] G. Liu, Y. Shao, K. Ma, Q. Cui, F. Wu, S. Xu, Synthesis of DNA-templated fluorescent gold nanoclusters, Gold Bull. 45 (2012) 69-74. doi:10.1007/s13404-012-0049-6.

[113] G. Liu, Y. Shao, F. Wu, S. Xu, J. Peng, L. Liu, DNA-hosted fluorescent gold nanoclusters: sequence-dependent formation, Nanotechnology. $24 \quad$ (2013) 015503. doi:10.1088/0957-4484/24/1/015503. 
[114] M. Hosseini, E. Ahmadi, Y.-S. Borghei, M. Reza Ganjali, A new fluorescence turn-on nanobiosensor for the detection of micro-RNA-21 based on a DNA - gold nanocluster, Methods Appl. Fluoresc. 5 (2017) 015005. doi:10.1088/2050-6120/aa5e57.

[115] J. Xie, Y. Zheng, J.Y. Ying, Protein-Directed Synthesis of Highly Fluorescent Gold Nanoclusters, J. Am. Chem. Soc. 131 (2009) 888-889. doi:10.1021/ja806804u.

[116] B.A. Russell, P.A. Mulheran, D.J.S. Birch, Y. Chen, Probing the Sudlow binding site with warfarin: how does gold nanocluster growth alter human serum albumin?, Phys. Chem. Chem. Phys. 18 (2016) 22874-22878. doi:10.1039/C6CP03428D.

[117] B.A. Russell, B. Jachimska, P. Komorek, P.A. Mulheran, Y. Chen, Lysozyme encapsulated gold nanoclusters: effects of cluster synthesis on natural protein characteristics, Phys. Chem. Chem. Phys. 19 (2017) 7228-7235. doi:10.1039/C7CP00540G,

[118] Y. Wang, J.-T. Chen, X.-P. Yan, Fabrication of Transferrin Functionalized Gold Nanoclusters/Graphene Oxide Nanocomposite for Turn-On Near-Infrared Fluorescent Bioimaging of Cancer Cells and Small Animals, Anal. Chem. 85 (2013) 2529-2535. doi:10.1021/ac303747t.

[119] K. Chaudhari, P.L. Xavier, T. Pradeep, Understanding the Evolution of Luminescent Gold Quantum Clusters in Protein Templates, ACS Nano. 5 (2011) 8816-8827. doi:10.1021/nn202901a.

[120] J.-M. Liu, J.-T. Chen, X.-P. Yan, Near Infrared Fluorescent Trypsin Stabilized Gold Nanoclusters as Surface Plasmon Enhanced Energy Transfer Biosensor and in Vivo Cancer Imaging Bioprobe, Anal. Chem. 85 (2013) 3238-3245. doi:10.1021/ac303603f.

[121] H. Kawasaki, K. Hamaguchi, I. Osaka, R. Arakawa, ph-Dependent Synthesis of Pepsin-Mediated Gold Nanoclusters with Blue Green and Red Fluorescent Emission, Adv. Funct. Mater. 21 (2011) 3508-3515. doi:10.1002/adfm.201100886.

[122] C.-L. Liu, H.-T. Wu, Y.-H. Hsiao, C.-W. Lai, C.-W. Shih, Y.-K. Peng, K.-C. Tang, H.-W. Chang, Y.-C. Chien, J.-K. Hsiao, J.-T. Cheng, P.-T. Chou, Insulin-Directed Synthesis of Fluorescent Gold Nanoclusters: Preservation of Insulin Bioactivity and Versatility in Cell Imaging, Angew. Chem. Int. Ed. 50 (2011) 7056-7060. doi:10.1002/anie.201100299.

[123] F. Wen, Y. Dong, L. Feng, S. Wang, S. Zhang, X. Zhang, Horseradish Peroxidase Functionalized Fluorescent Gold Nanoclusters for Hydrogen Peroxide Sensing, Anal. Chem. 83 (2011) 1193-1196. doi:10.1021/ac1031447.

[124] S.K. Mudedla, E.R.A. Singam, J. Vijay Sundar, M.N. Pedersen, N.A. Murugan, J. Kongsted, H. Ågren, V. Subramanian, Enhancement of Internal Motions of Lysozyme through Interaction with Gold Nanoclusters and its Optical Imaging, J. Phys. Chem. C. 119 (2015) 653-664. doi:10.1021/jp508582c.

[125] U. Prisco, C. Leung, C. Xirouchaki, C.H. Jones, J.K. Heath, R.E. Palmer, Residuespecific immobilization of protein molecules by size-selected clusters, J. R. Soc. Interface. 2 (2005) 169-175. doi:10.1098/rsif.2005.0032.

[126] W. Zhang, J. Ye, Y. Zhang, Q. Li, X. Dong, H. Jiang, X. Wang, One-step facile synthesis of fluorescent gold nanoclusters for rapid bio-imaging of cancer cells and small animals, RSC Adv, 5 (2015) 63821-63826. doi:10.1039/C5RA11321K.

[127] Y. Xu, J. Sherwood, Y. Qin, D. Crowley, M. Bonizzoni, Y. Bao, The role of protein characteristics in the formation and fluorescence of Au nanoclusters, Nanoscale. 6 (2014) 1515-1524. doi:10.1039/C3NR06040C.

[128] T.-H. Chen, W.-L. Tseng, (Lysozyme Type VI)-Stabilized Au8 Clusters: Synthesis Mechanism and Application for Sensing of Glutathione in a Single Drop of Blood, Small. 8 (2012) 1912-1919. doi:10.1002/smll.201102741.

[129] J. Wang, G. Zhang, Q. Li, H. Jiang, C. Liu, C. Amatore, X. Wang, In vivo self-bioimaging of tumors through in situ biosynthesized fluorescent gold nanoclusters, Sci. Rep. 3 (2013). doi:10.1038/srep01157. 
[130] A.L. West, N.M. Schaeublin, M.H. Griep, E.I. Maurer-Gardner, D.P. Cole, A.M. Fakner, S.M. Hussain, S.P. Karna, In situ Synthesis of Fluorescent Gold Nanoclusters by Nontumorigenic Microglial Cells, ACS Appl. Mater. Interfaces. 8 (2016) 21221-21227. doi:10.1021/acsami.6b06624.

[131] Y. Kong, J. Chen, F. Gao, R. Brydson, B. Johnson, G. Heath, Y. Zhang, L. Wu, D. Zhou, Near-infrared fluorescent ribonuclease-A-encapsulated gold nanoclusters: preparation, characterization, cancer targeting and imaging, Nanoscale. 5 (2013) 1009-1017. doi:10.1039/C2NR32760K.

[132] S. Chattoraj, M.A. Amin, K. Bhattacharyya, Cytochrome $c$-Capped Fluorescent Gold Nanoclusters: Imaging of Live Cells and Delivery of Cytochrome $c$, ChemPhysChem. 17 (2016) 2088-2095. doi:10.1002/cphc.201501163.

[133] S. Chattoraj, A. Amin, B. Jana, S. Mohapatra, S. Ghosh, K. Bhattacharyya, Selective Killing of Breast Cancer Cells by Doxorubicin-Loaded Fluorescent Gold Nanoclusters: Confocal Microscopy and FRET, ChemPhysChem. 17 (2016) 253-259. doi:10.1002/cphc.201500982.

[134] H. Li, Y. Cheng, Y. Liu, B. Chen, Fabrication of folic acid-sensitive gold nanoclusters for turn-on fluorescent imaging of overexpression of folate receptor in tumor cells, Talanta. 158 (2016) 118-124. doi:10.1016/j.talanta.2016.05.038.

[135] J. Lin, Z. Zhou, Z. Li, C. Zhang, X. Wang, K. Wang, G. Gao, P. Huang, D. Cui, Biomimetic one-pot synthesis of gold nanoclusters/nanoparticles for targeted tumor cellular dual-modality imaging, Nanoscale Res. Lett. 8 (2013) 170. doi:10.1186/1556-276X-8-170.

[136] R. Khandelia, S. Bhandari, U.N. Pan, S.S. Ghosh, A. Chattopadhyay, Gold Nanocluster Embedded Albumin Nanoparticles for Two-Photon Imaging of Cancer Cells Accompanying Drug Delivery, Small. 11 (2015) 4075-4081. doi:10.1002/smll.201500216.

[137] X. Wu, X. He, K. Wang, C. Xie, B. Zhou, Z. Qing, Ultrasmall near-infrared gold nanoclusters for tumor fluorescence imaging in vivo, Nanoscale. 2 (2010) 2244. doi:10.1039/c0nr00359j.

[138] W. Zhang, J. Ye, Y. Zhang, Q. Li, X. Dong, H. Jiang, X. Wang, One-step facile synthesis of fluorescent gold nanoclusters for rapid bio-imaging of cancer cells and small animals, RSC Adv. 5 (2015) 63821-63826. doi:10.1039/C5RA11321K.

[139] D. Hu, Z. Sheng, S. Fang, Y. Wang, D. Gao, P. Zhang, P. Gong, Y. Ma, L. Cai, Folate Receptor-Targeting Gold Nanoclusters as Fluorescence Enzyme Mimetic Nanoprobes for Tumor Molecular Colocalization Diagnosis, Theranostics. 4 (2014) 142-153. doi: $10.7150 /$ thno.7266.

[140] F. Zhou, B. Feng, H. Yu, D. Wang, T. Wang, J. Liu, Q. Meng, S. Wang, P. Zhang, Z. Zhang, Y. Li, Cisplatin Prodrug-Conjugated Gold Nanocluster for Fluorescence Imaging and Targeted Therapy of the Breast Cancer, Theranostics. 6 (2016) 679-687. doi:10.7150/thno.14556.

[141] S. Su, H. Wang, X. Liu, Y. Wu, G. Nie, iRGD-coupled responsive fluorescent nanogel for targeted drug delivery, Biomaterials. $34 \quad$ (2013) 3523-3533. doi:10.1016/j.biomaterials.2013.01.083.

[142] T. Chen, S. Xù, T. Zháo, L. Zhu, D. Wei, Y. Li, H. Zhang, C. Zhao, Gold NanoclusterConjugated Amphiphilic Block Copolymer for Tumor-Targeted Drug Delivery, ACS Appl. Mater. Interfaces. 4 (2012) 5766-5774. doi:10.1021/am301223n.

[143] Y. Liu, G.-F. Tian, X.-W. He, W.-Y. Li, Y.-K. Zhang, Microwave-assisted one-step rapid synthesis of near-infrared gold nanoclusters for NIRF/CT dual-modal bioimaging, $J$ Mater Chem B. 4 (2016) 1276-1283. doi:10.1039/C5TB02322J.

[144] Y. Wang, C. Xu, J. Zhai, F. Gao, R. Liu, L. Gao, Y. Zhao, Z. Chai, X. Gao, LabelFree Au Cluster Used for in Vivo 2D and 3D Computed Tomography of Murine Kidneys, Anal. Chem. 87 (2015) 343-345. doi:10.1021/ac503887c. 
[145] A.R. Garcia, I. Rahn, S. Johnson, R. Patel, J. Guo, J. Orbulescu, M. Micic, J.D. Whyte, P. Blackwelder, R.M. Leblanc, Human insulin fibril-assisted synthesis of fluorescent gold nanoclusters in alkaline media under physiological temperature, Colloids Surf. B Biointerfaces. 105 (2013) 167-172. doi:10.1016/j.colsurfb.2012.12.052.

[146] F. Ghahremani, D. Shahbazi-Gahrouei, A. Kefayat, H. Motaghi, M.A. Mehrgardi, S.H. Javanmard, AS1411 aptamer conjugated gold nanoclusters as a targeted radiosensitizer for megavoltage radiation therapy of 4T1 breast cancer cells, RSC Adv. 8 (2018) 4249-4258. doi:10.1039/C7RA11116A.

[147] X.-D. Zhang, D. Wu, X. Shen, P.-X. Liu, F.-Y. Fan, S.-J. Fan, In vivo renal clearance, biodistribution, toxicity of gold nanoclusters, Biomaterials. 33 (2012) 4628-4638. doi:10.1016/j.biomaterials.2012.03.020. 


\section{Figures and Captions}

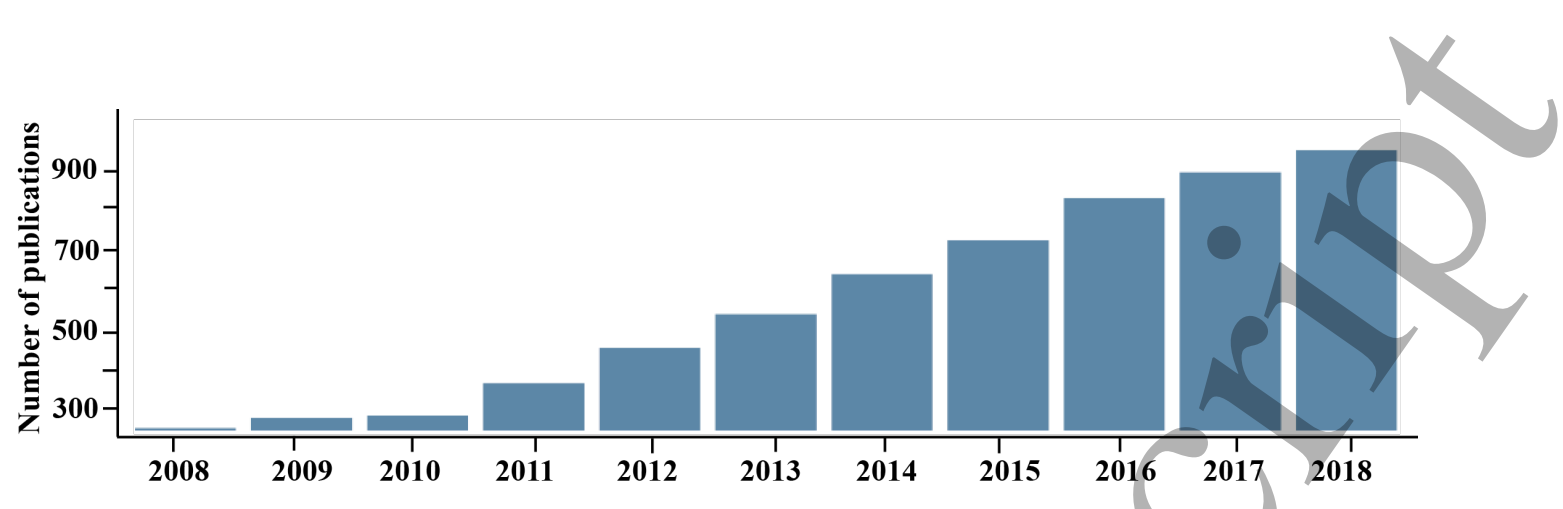

Figure 1. Trend analysis of scientific publications of the searched term "Gold nanoclusters" within 2008-2018 according to Thomson Reuters Web of Science ${ }^{\mathrm{TM}}$ database, January 2019. 
(a)

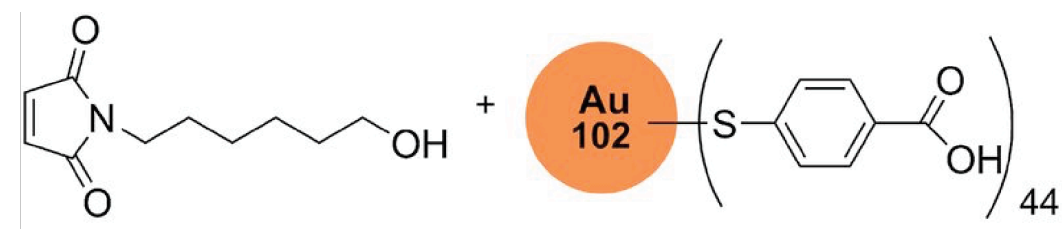

1) $\mathrm{DCC} / \mathrm{DMSO} / \mathrm{CH}_{2} \mathrm{Cl}_{2}$

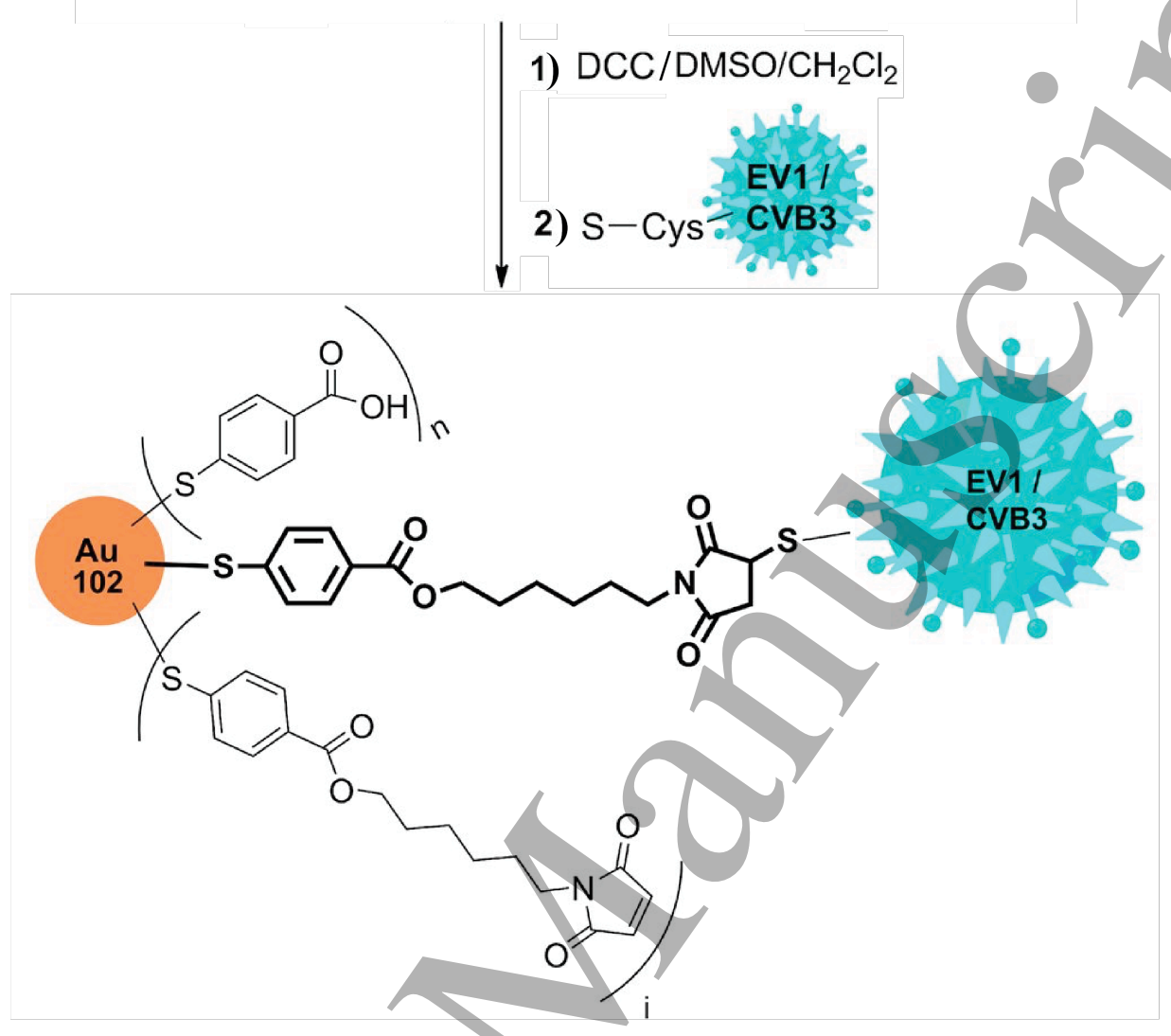

(b)

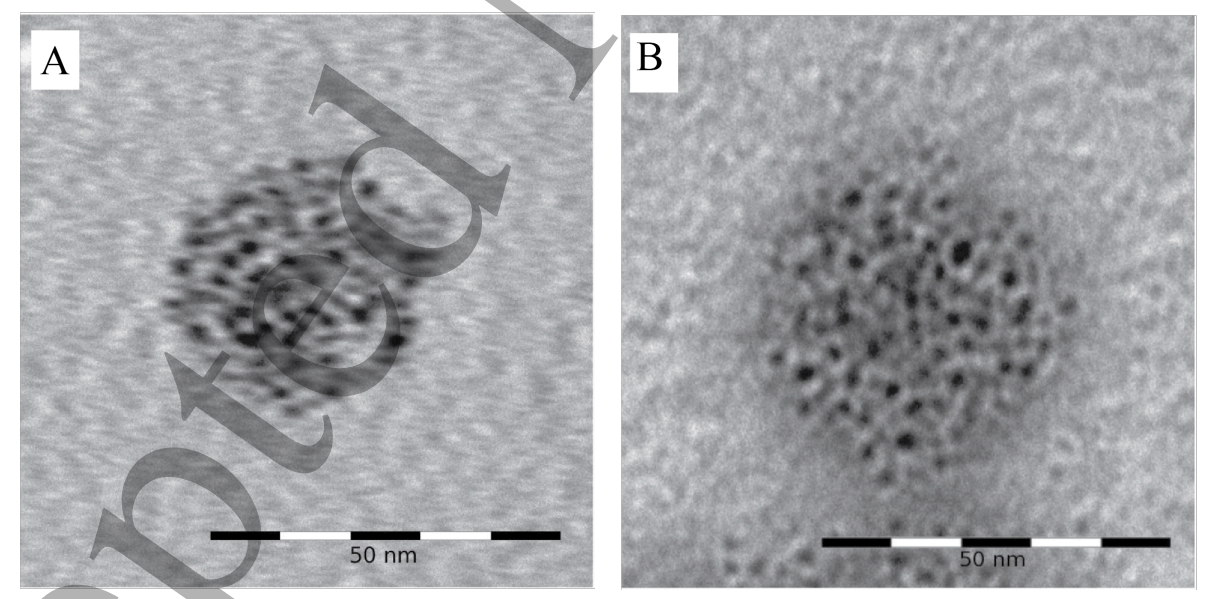

Figure 2. a) Schematic representation of non-fluorescent AuNCs site-specific conjugation to enteroviruses (EV1 or CVB3); b) TEM images: (A) CVB3 incubated for 2 days with $\mathrm{Au}_{102}$ MI clusters, after column purification, (B) EV1 incubated with $\mathrm{Au}_{102}-\mathrm{MI}$ for 1 day. TEM magnification: (A) $2 \times 105$, (B) $1 \times 105$. Reproduced with permission from ref. [55], copyright 2014 National Academy of Sciences . 

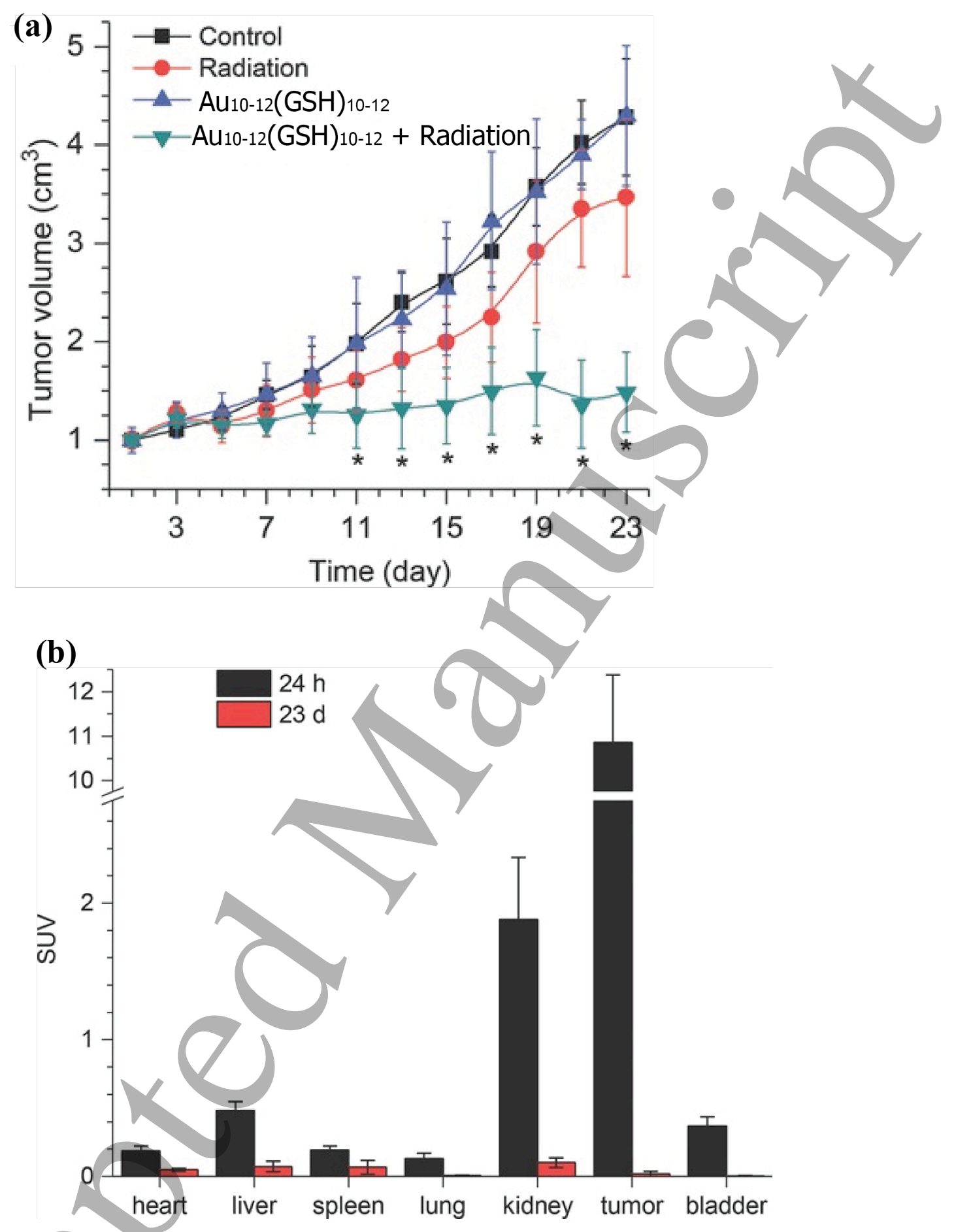

Figure 3. The in vivo behavior of $\mathrm{Au}_{10-12}(\mathrm{GSH})_{10-12}$ : a) Tumor volumes evaluation of untreated mice (control), mice treated only with radiation, mice treated only with $\mathrm{Au}_{10-12}(\mathrm{SG})_{10-12}$ and mice treated with both, radiation and $\mathrm{Au}_{10-12}(\mathrm{GSH})_{10-12}$. b) Biodistribution studies of $\mathrm{Au}_{10-12}(\mathrm{GSH})_{10-12}$ at $24 \mathrm{~h}$ and 23 days post injection. Reproduced with permission from ref. [62]. 
(a)

(b)
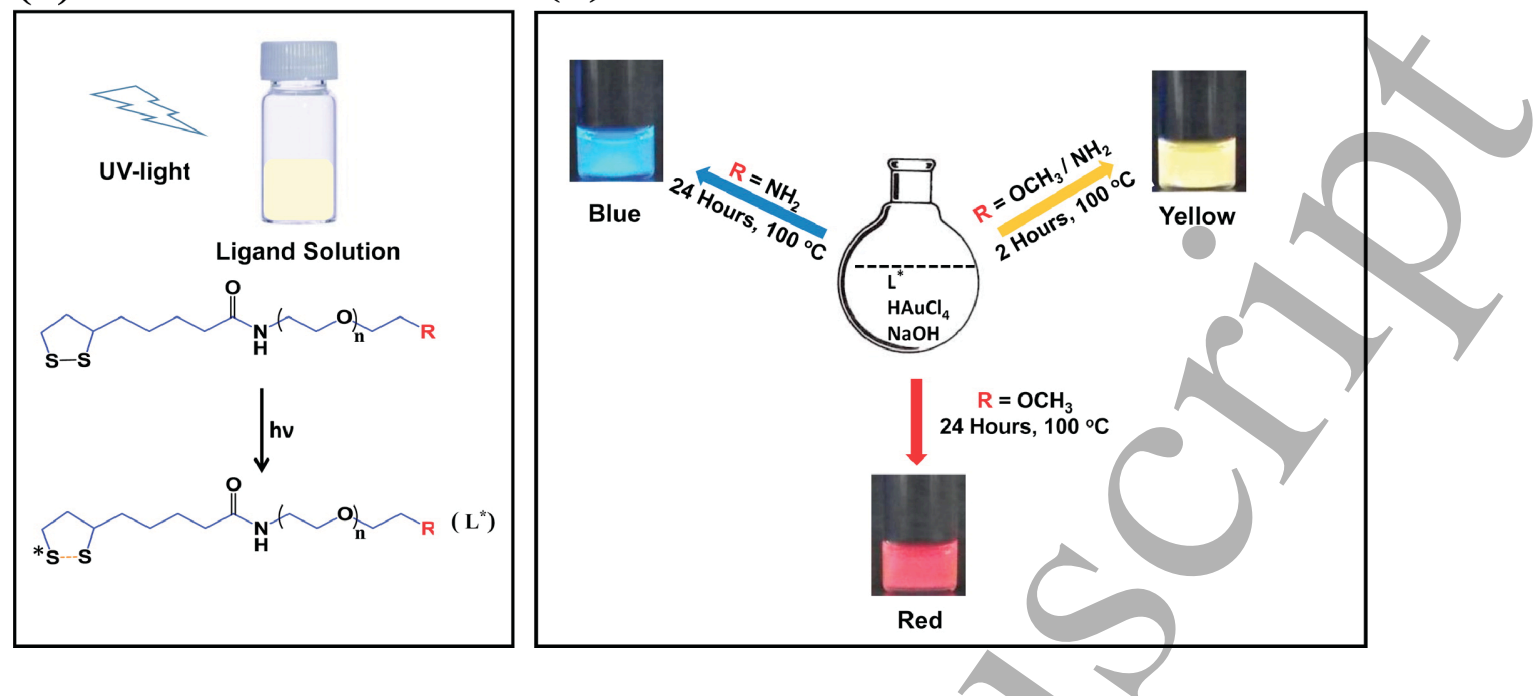

Figure 4. Schematic preparation of fluorescent AuNCs: a) Step 1: ligand irradiation under UV light ( $350 \mathrm{~nm}$ ) followed by step 2: growth of AuNCs with tunable emission represented in (b). Reproduced with permission from ref. [74]. Copyright 2016 American Chemical Society. 
(a)

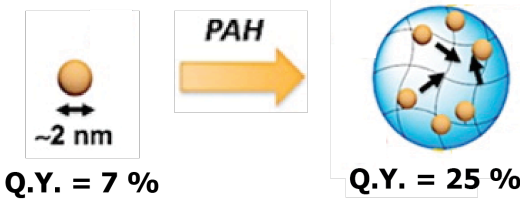

(b)

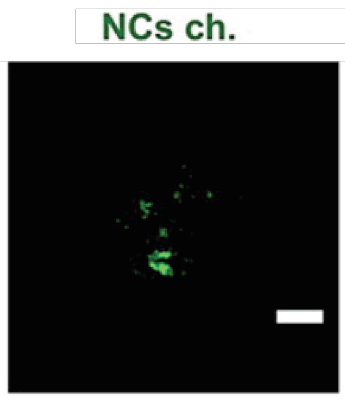

AuGSHPAH
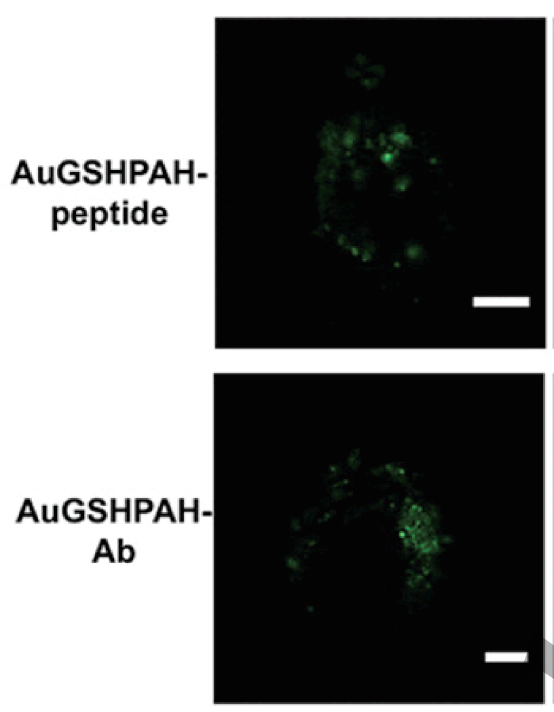

Alexa647 ch.
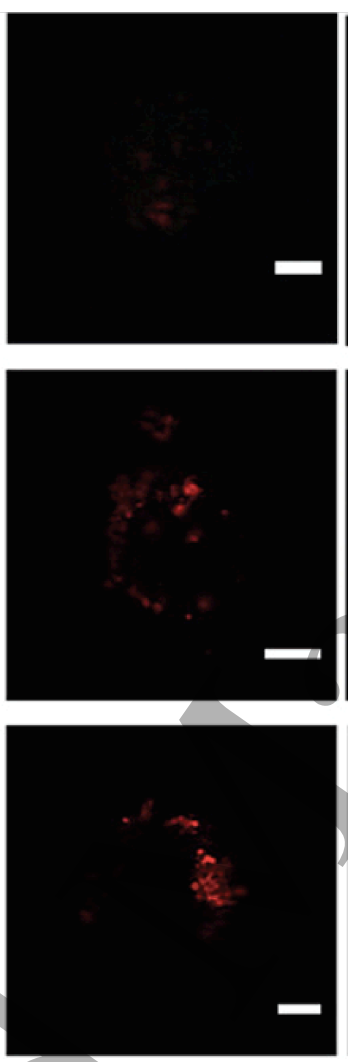

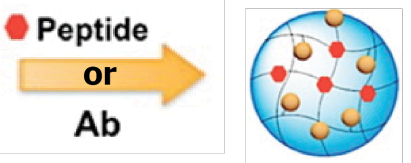

Ab
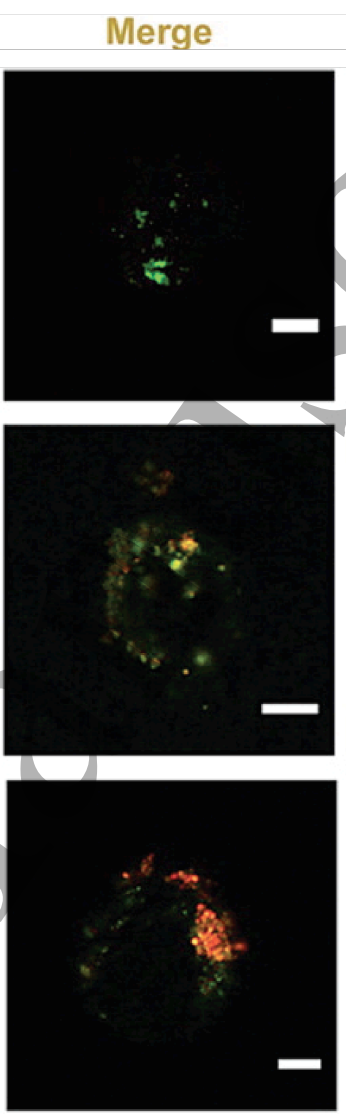

Merge-BF
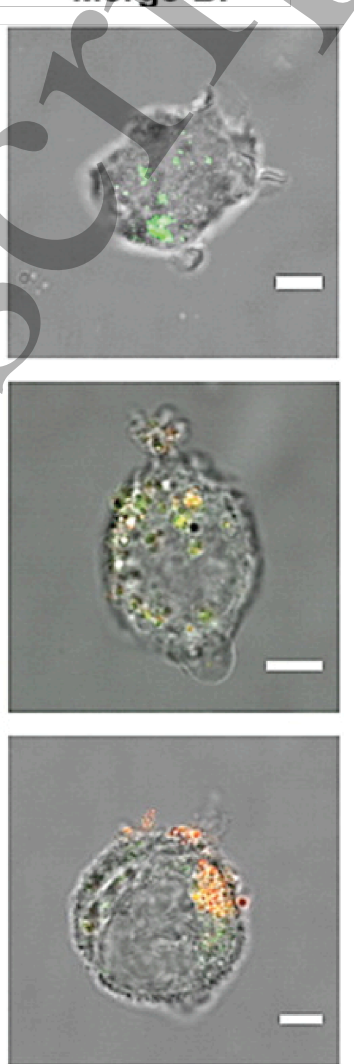

Figure 5. a) Schematic preparation of PAH-GSH-AuNCs nanogel by crosslinking GSHAuNCs with a cationic polymer (PAH); b) Confocal laser scanning microscopy (CLSM) images of THP1 cells incubated with PAH-GSH-AuNCs, peptide-PAH-GSH-AuNCs and AbPAH-GSH-AuNCs for $24 \mathrm{~h}$. Nanocarriers were visible with the NC channel (green, 550-620 $\mathrm{nm}$ ), peptide and antibody with the Alexa647 channel (red, 650-800 nm); bars: $5 \mu \mathrm{m}$. Reproduced with permission from ref. [93]. Copyright 2016 American Chemical Society. 


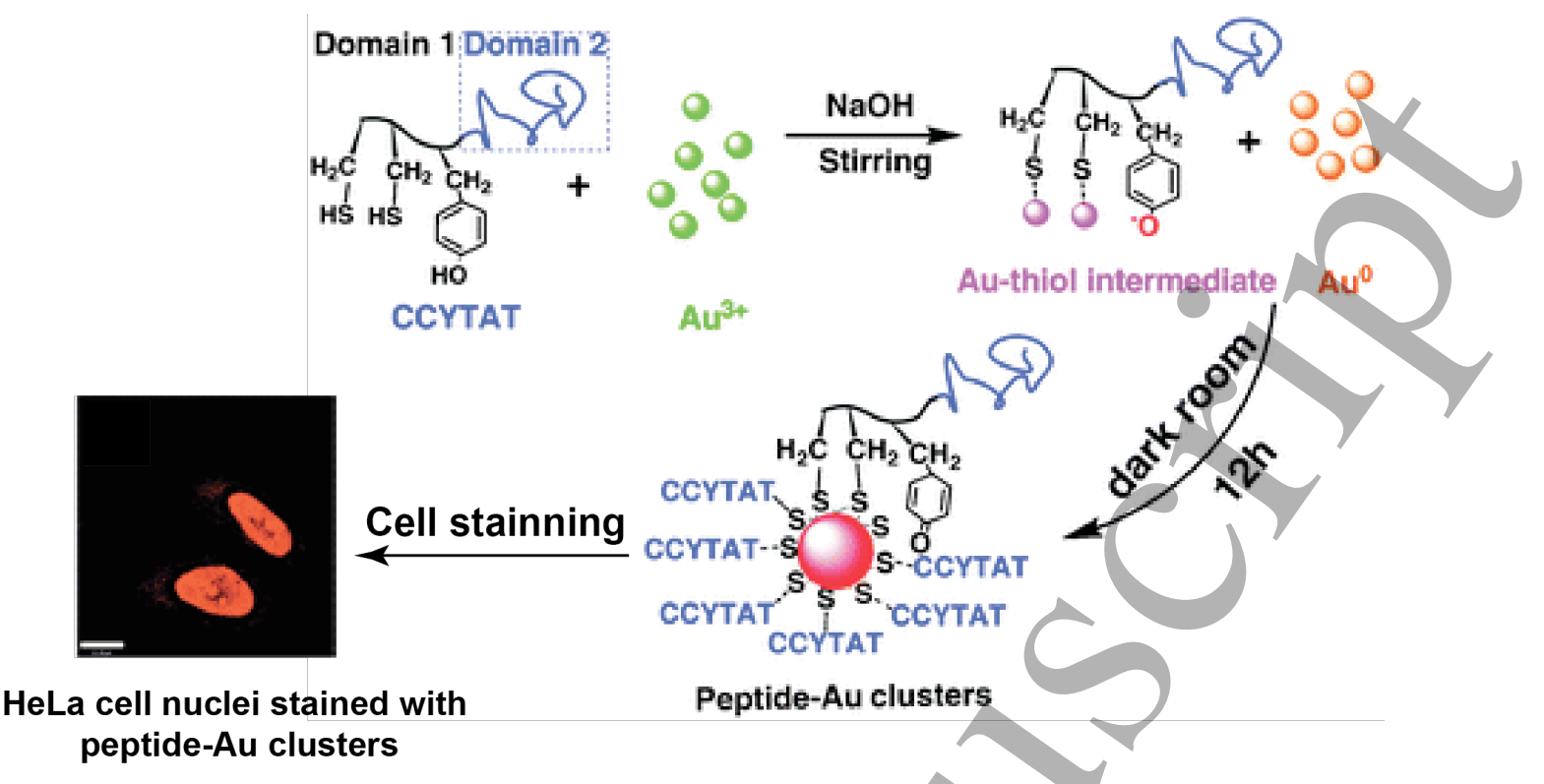

Figure 6. Fluorescent peptide-AuNCs preparation: the thiol enriched domain I captures $\mathrm{Au}$ ions and forms an intermediate $\mathrm{Au}-\mathrm{S}$ product then the addition of $\mathrm{NaOH}$ determines the phenolic group of tyrosine to change into a phenoxide ion, which can reduce $\mathrm{Au}$ ions. The resulting $\mathrm{Au}$ atoms aggregate and are coordinated by $\mathrm{SH}$ groups of the peptide. Domain II of the peptide targets the cell nucleus. Reproduced with permission from ref. [94]. 

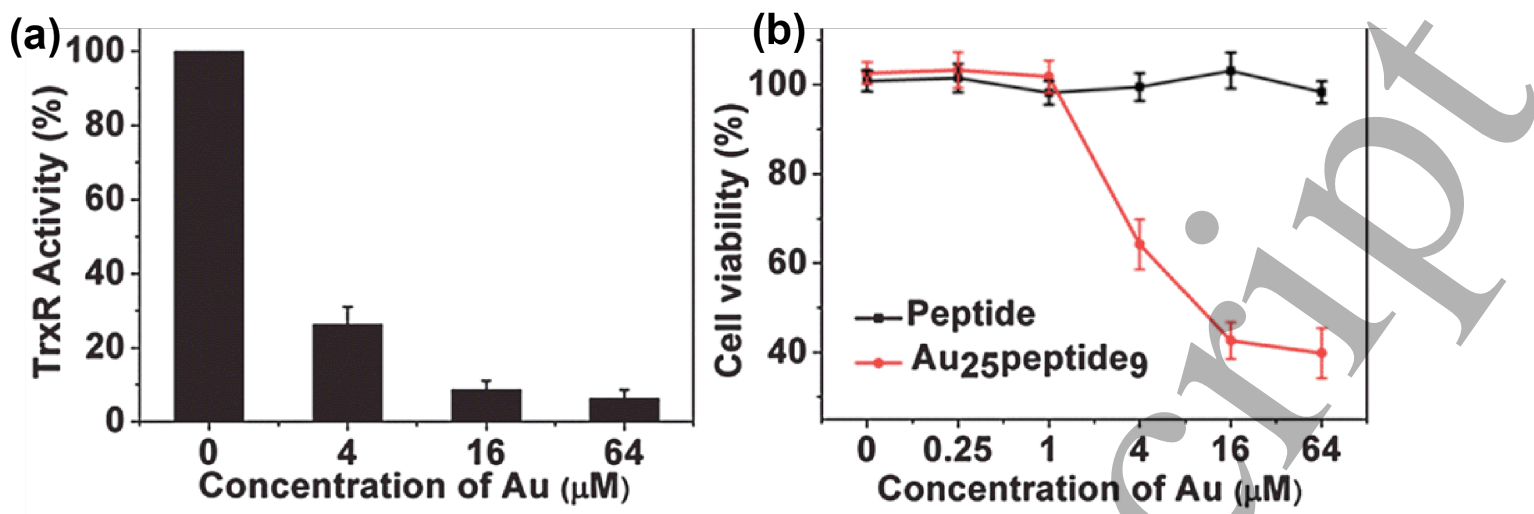

(c)

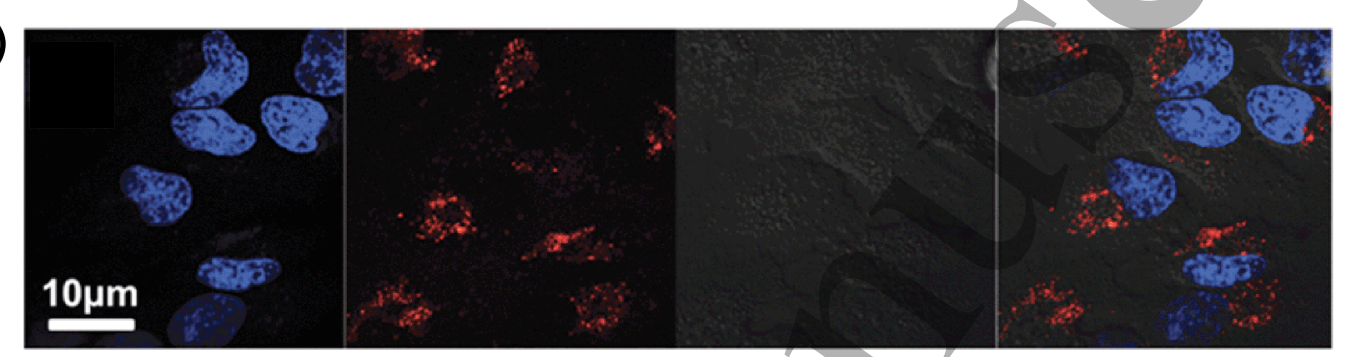

Figure 7. a) TrxR1 activity is suppressed in a dose dependent manner when treated with serial doses of fluorescent $\mathrm{Au}_{25} \mathrm{NCs}-$ peptide 9 (peptide: CCYGGPKKKRKVG); b) Cell viability ratio of $\mathrm{HeLa}$ cells when treated with free peptide and $\mathrm{Au}_{25} \mathrm{NCs}-$ peptide 9 for $36 \mathrm{~h}$. c) Confocal studies of HeLa cells exposed to culture media containing $16 \mu \mathrm{M} \mathrm{Au}{ }_{25} \mathrm{NCs}$-peptide 9 for $36 \mathrm{~h}$. The $\mathrm{Au}_{25} \mathrm{NCs}-$ peptide 9 were, transported into HeLa cells and located in the cytoplasm (excitation/emission at $560 \mathrm{~nm} / 615 \mathrm{~nm}$ ). Reproduced with permission from ref. [95]. 

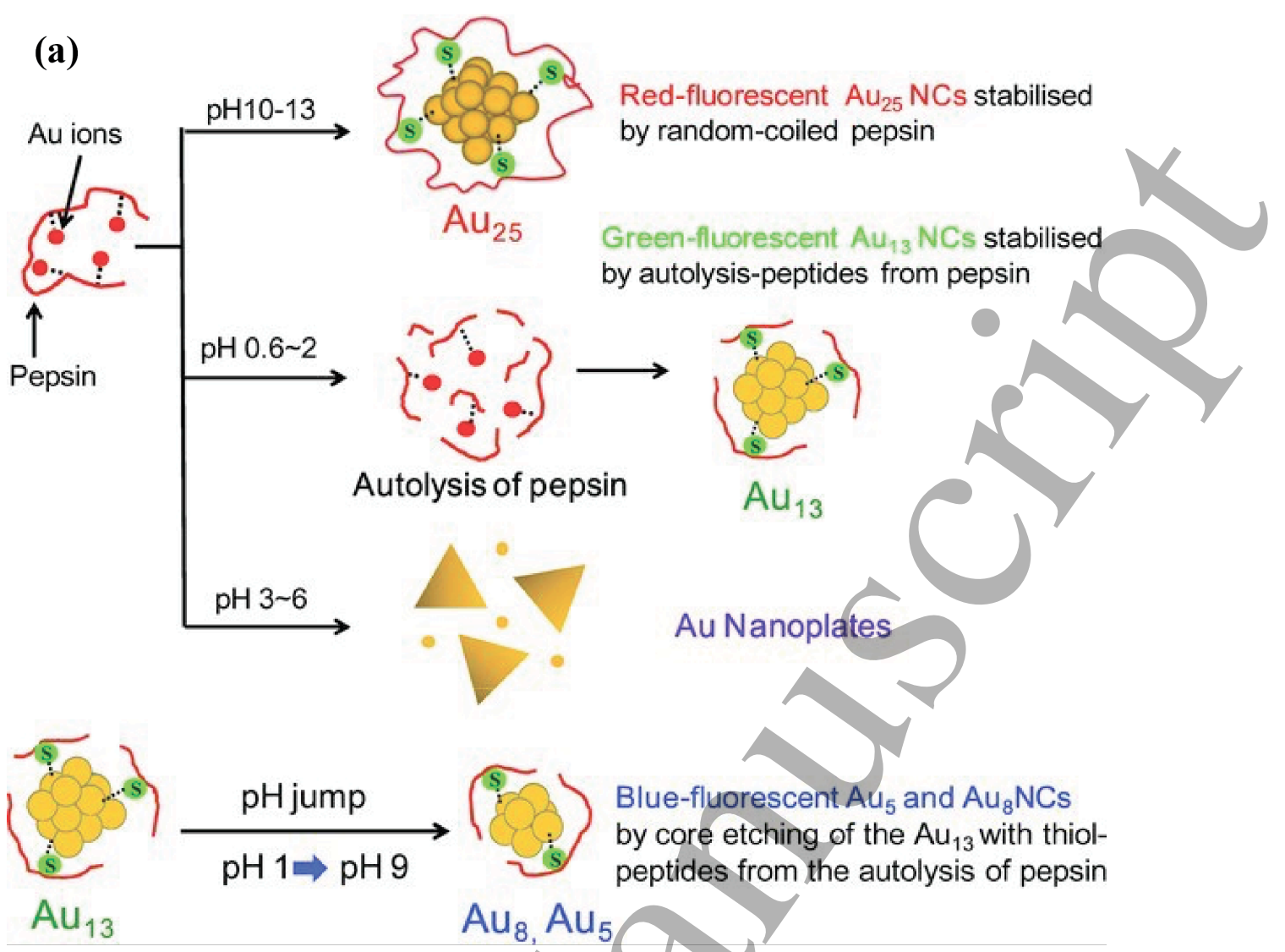

(b)

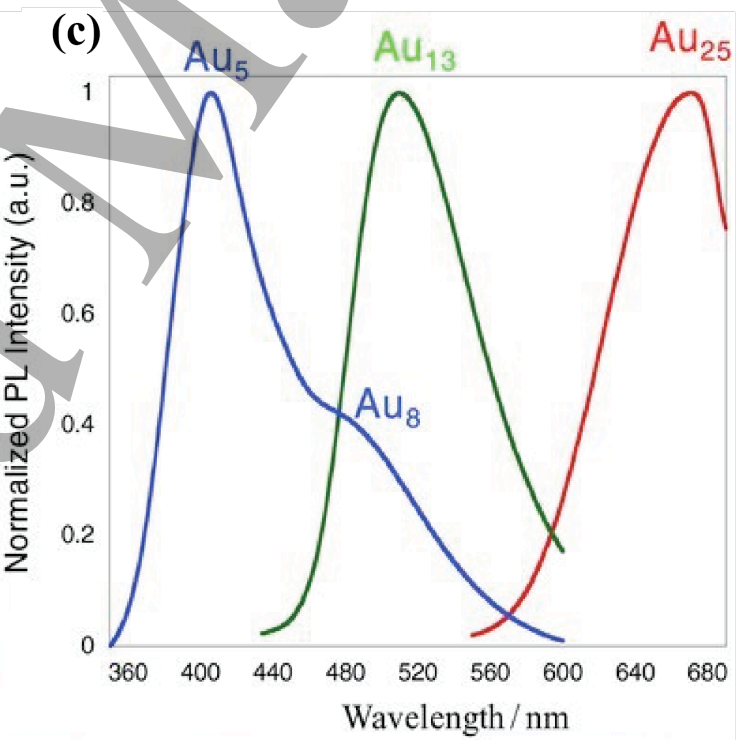

Figure 8. a) Illustration of the $\mathrm{pH}-\mathrm{dependent}$ synthesis of pepsin-AuNCs with blue-, green-, and red-fluorescent emissions. b) Pepsin-mediated AuNCs with red, green, and blue emission under UV light (above) or visible light (below) in aqueous solutions; c) Fluorescence spectra of aqueous solutions of pepsin-AuNCs with red (sample I, $\mathrm{Au}_{25}$ ) at $\mathrm{pH} 12$, green (sample II, $\mathrm{Au}_{13}$ ) at $\mathrm{pH} 1$, and blue (sample III, $\mathrm{Au}_{5}$ and $\mathrm{Au}_{8}$ ) emission at $\mathrm{pH}$ 9. Reproduced with permission from ref. [121]. 
(a)
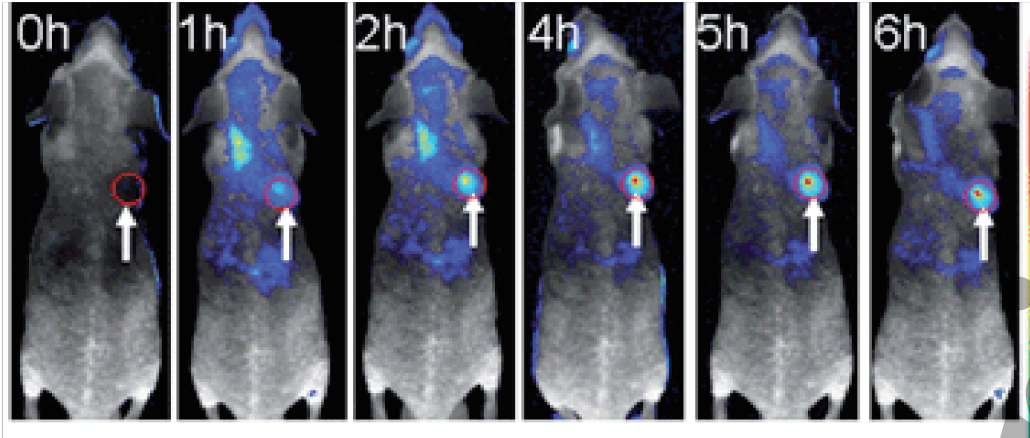

(b)

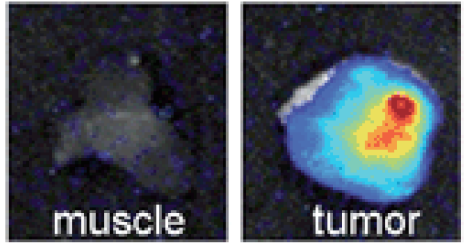

Figure 9. a) Fluorescence images of mice bearing an MDA-MB-45 tumor. Strong signal from AuNCs was observed in the tumor (marked by the red circle), demonstrating significant passive accumulation in the tumor by the EPR effect. The arrowheads indicated the tumor. b) Ex vivo fluorescence image of the tumor tissue and the muscle tissue around the tumor from the mice used in (a). Reproduced with permission from ref. [137]. 
(a)

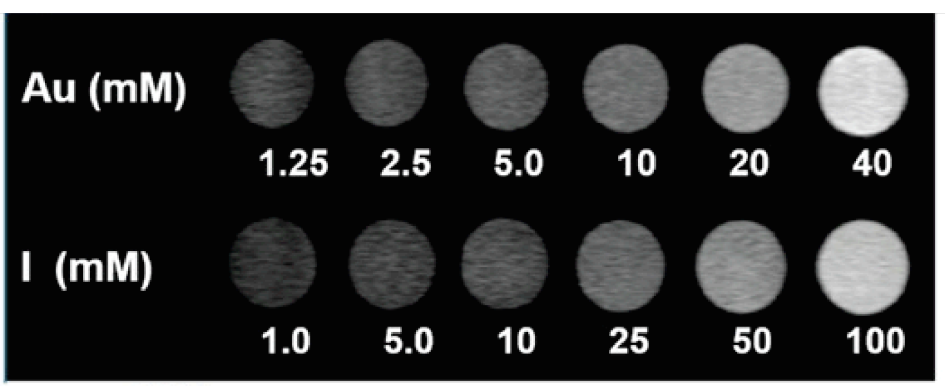

(b)

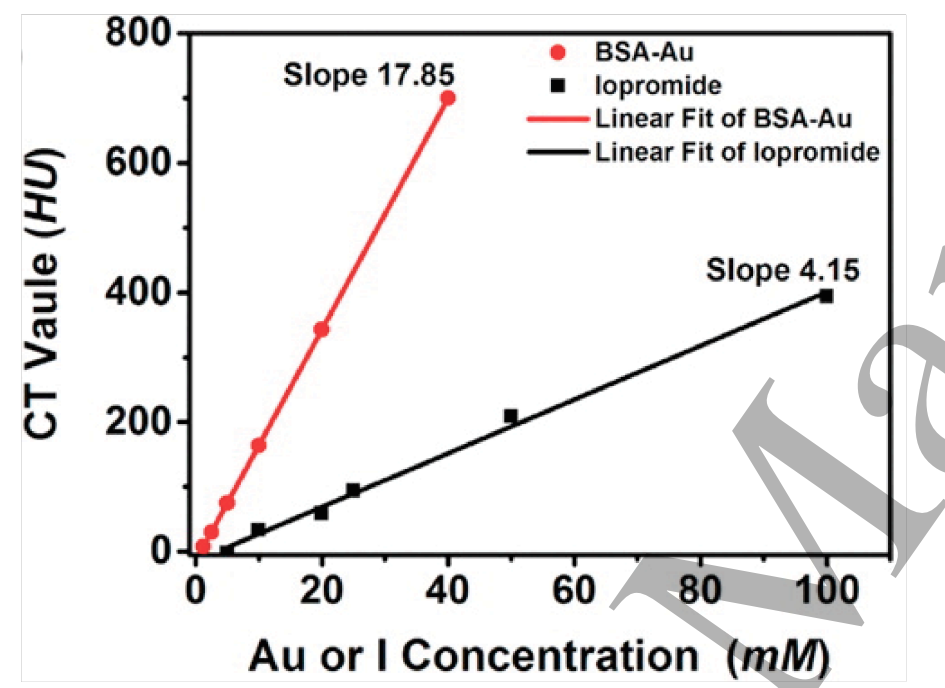

Prone Position

(c) Control

BSA-Au
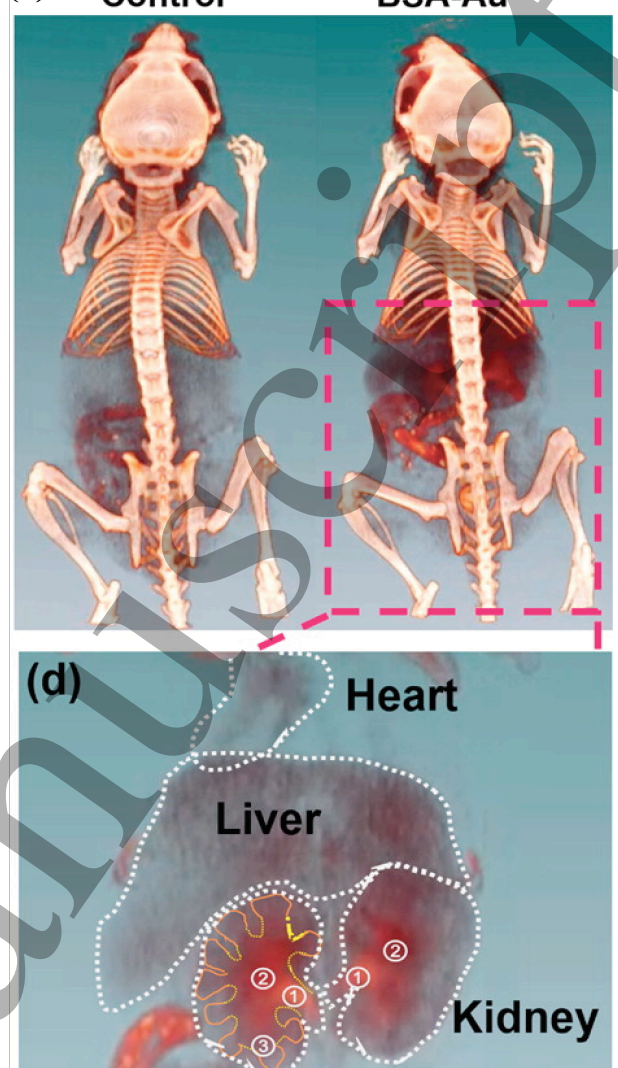

Kidney

\section{Bladder}

\section{Enlarged View}

Figure 10. a) Computed tomography (CT) showing the contrasting ability of BSA-AuNCs in comparion to iopromide solution at different concentrations; b) The HU values of BSAAuNCs and iopromide as a function of the Au and I concentrations; c) In vivo twodimensional CT images of mice injected with saline (left) and BSA-AuNCs (right) $2 \mathrm{~h}$ post injection; d) The enlarged view shows the ureter (1), renal pelvis (2), major calyx (3) and the kidneys marked with dashed curves. Reproduced with permission from ref. [144]. Copyright 2015 American Chemical Society. 
Table 1. Selected exemples of biocompatible proteins-AuNCs and their area of applications

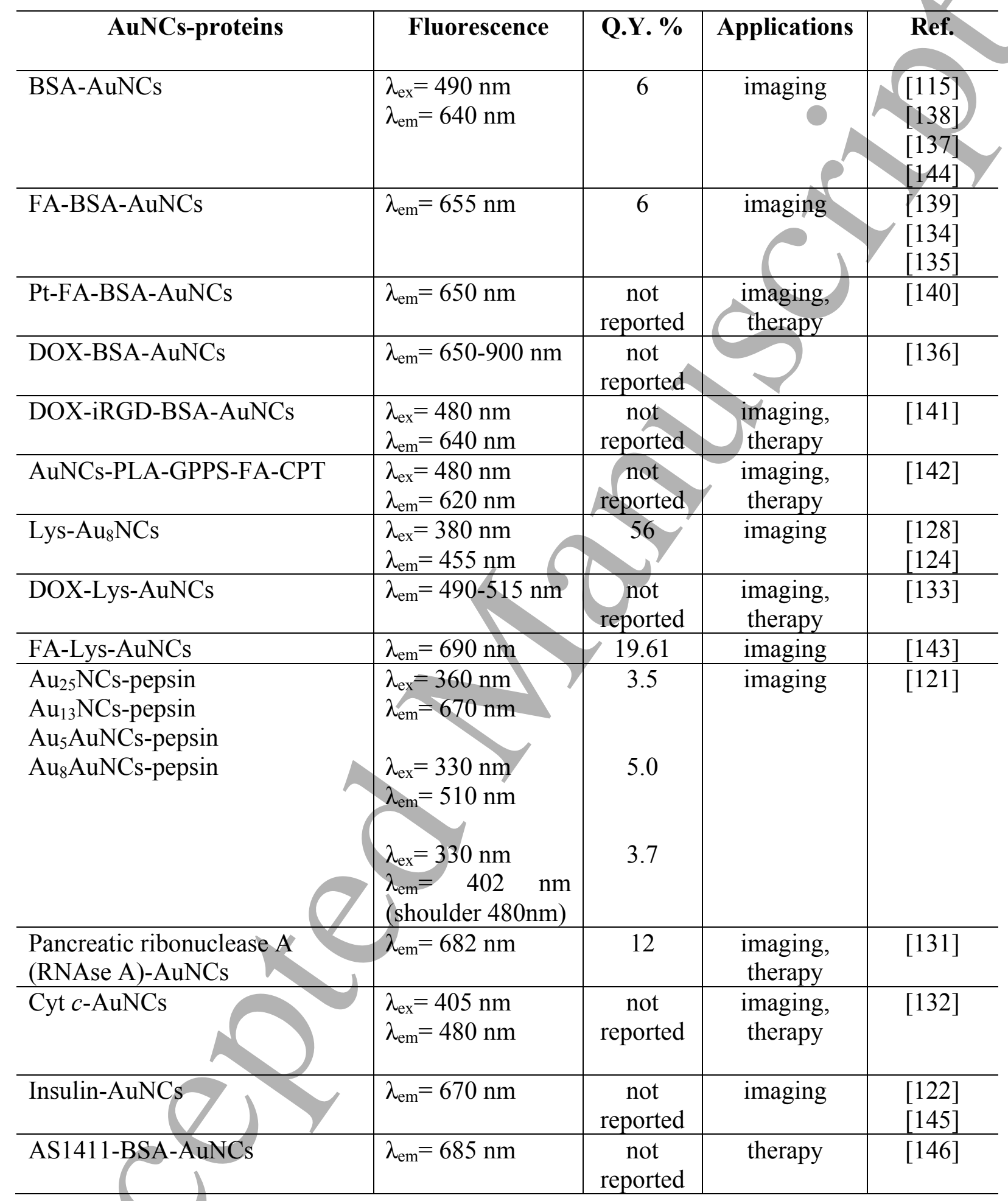

